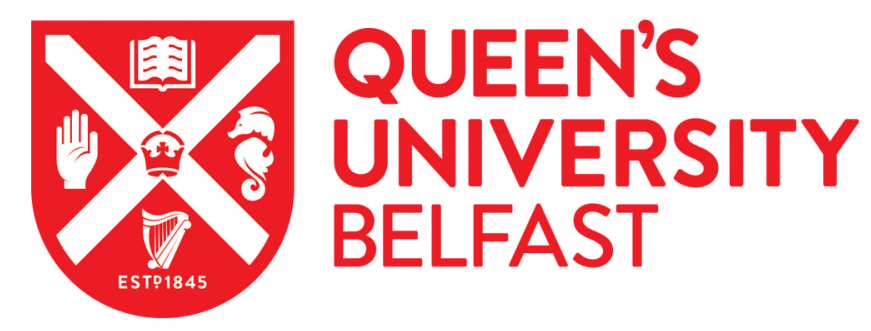

\title{
Holocene establishment of mangrove forests in the western coast of the Gulf of Mexico
}

Cordero-Oviedo, C., Correa-Metrio, A., Urrego, L. E., Vázquez-Hurtado, G., Blaauw, M., Escobar, J., \& Curtis, J. $\mathrm{H}$. (2019). Holocene establishment of mangrove forests in the western coast of the Gulf of Mexico. CATENA, 180, 212-223. https://doi.org/10.1016/j.catena.2019.04.025

\section{Published in: \\ CATENA}

\section{Document Version:}

Peer reviewed version

\section{Queen's University Belfast - Research Portal:}

Link to publication record in Queen's University Belfast Research Portal

\section{Publisher rights}

Copyright 2019Elsevier.

This manuscript is distributed under a Creative Commons Attribution-NonCommercial-NoDerivs License

(https://creativecommons.org/licenses/by-nc-nd/4.0/), which permits distribution and reproduction for non-commercial purposes, provided the author and source are cited.

\section{General rights}

Copyright for the publications made accessible via the Queen's University Belfast Research Portal is retained by the author(s) and / or other copyright owners and it is a condition of accessing these publications that users recognise and abide by the legal requirements associated with these rights.

Take down policy

The Research Portal is Queen's institutional repository that provides access to Queen's research output. Every effort has been made to ensure that content in the Research Portal does not infringe any person's rights, or applicable UK laws. If you discover content in the Research Portal that you believe breaches copyright or violates any law, please contact openaccess@qub.ac.uk. 
Elsevier Editorial system(tm) for Catena Manuscript Draft

Manuscript Number: CATENA7971R1

Title: Holocene establishment of mangrove forests in the western coast of the Gulf of Mexico

Article Type: Research Paper

Keywords: coastal environment; Gulf of Mexico; Holocene; mangroves; sealevel changes; pollen analysis

Corresponding Author: Dr. Alexander Correa-Metrio,

Corresponding Author's Institution:

First Author: Cecilia Cordero-Oviedo

Order of Authors: Cecilia Cordero-Oviedo; Alexander Correa-Metrio; Ligia Estela Urrego; Gabriela Vázquez-Hurtado; Maarten Blaauw; Jaime Esconar; Jason Curtis

Abstract: The successful establishment of mangrove ecosystems depends on an intricate network of interactions among physical and biological factors that are highly dynamic through time. At millennial to centennial time scales, regional climates, sea levels, and local geomorphology play critical roles in the establishment of mangroves. Whereas fluvio-marine dynamics define coastal sedimentary settings, regional precipitation and freshwater input modulate salinity and seasonal flooding patterns. We analyzed a 7800-year-old, continuous sedimentary record from the western coast of the Gulf of Mexico to shed light on regional biophysical coastal processes and the history of the mangroves that occupy the region today. We used a systematic sampling of mud-water interface sediments to generate a modern reference frame for interpreting fossil pollen assemblages. Our results indicate that the cored location that is currently approximately at sea level, was below sea level from 7800 to 4000 calibrated years before present (cal BP). The establishment of dense mangrove stands took place around $3700 \mathrm{cal}$ BP, when regional sea levels stabilized, resulting in a substantial increase of organic matter and therefore carbon stored in the sediments. However, the mangrove ecological succession that started at 2000 cal BP was interrupted by a regional drought that extended from $\sim 5400$ to $3700 \mathrm{cal}$ BP. From $3700 \mathrm{cal}$ $\mathrm{BP}$ to Present, the lagoon has been characterized by relatively stable both substratum and sea level, that together have facilitated the establishment of mangrove forests. Overall, our record demonstrates the complexity of the interactions between local and regional factors in the development and evolution of both coastal geomorphology and ecosystems. 
Dear Dr. Cammeraat

We are happy to submit a revised version of the manuscript entitled "Holocene establishment of mangrove forests in the western coast of the Gulf of Mexico". We are very appreciative of the thorough review of the manuscript because it substantially improved it. The main change we made was including carbon and nitrogen analyses on both modern and fossil samples, giving more solid bases to our interpretations. We have included Jason Curtis and Jaime Escobar as coauthors because they very kindly contributed the $\mathrm{C}$ and $\mathrm{N}$ analysis and helped with the interpretation of results. Please find below the response to the queries from the reviewer, whereas the idiomatic suggestions marked on the pdf were directly attended on the word documents, which marked up copy we are attaching too. Please extend all our gratitude to the reviewer, he did a fantastic job at raising conceptual and stylistic concerns.

We feel that the new version is much better and stronger, we hope you find it suitable for publications in CATENA.

Sincerely yours,

Alex Correa-Metrio

Reviewer \#1: This paper provides a reconstruction of change in the La Mancha lagoon, on Mexico's east coast, based on pollen analysis. In fact, it relies almost entirely on pollen, with only a passing reference to stratigraphy. As the authors themselves note, the evolution of these coastal systems involves the complex interplay of a number of factors, a challenge that really needs a multi-proxy approach. There are some hints that there might be some other information available, but it is not presented (see below).

We are aware of the importance of a multiproxy approach, and thus, we have decided to add analyses of total both carbon and nitrogen in modern and fossil samples. The inclusion of new data has strengthened our case, but we, however, would like to emphasize that the aim of our research, as clearly stated in the manuscript, is reconstructing vegetation dynamics, a goal that is achieved through pollen analysis. Mangrove forests develop under a precise combination of geomorphologic settings as well as fluvial and marine influences, thus the use of mangrove pollen has been recognized as a reliable and efficient means for reconstructing environmental dynamics in costal environments.

The water level reconstructions in particular seem really quite speculative based on pollen alone and the lack of information about the morphology of the modern lagoon.

We have added a basic bathymetry based on data points that were measured during the collection of modern samples.

There are a number of places where more detail is needed and more justification for some of the reconstructions made. This need for clearer justification feeds through to the Highlights listed. Although the quality of the English was generally good, there were a few places where the meaning was not clear (see annotated pdf uploaded).

The document was changed according to the comments on the pdf. 


\section{Study area. More about the morphology of lagoon (is there anything in Reassert, 1999?) would be useful.}

We included a basic bathymetry. Also, in Section 2 (Study area), we abounded "La Mancha lagoon belongs to a geomorphic unit known as the Low Cumulative Plain that formed during the Quaternary (Geissert, 1999), allowing deposition of clayey-silt sediments. The lagoon formed at the margin of a volcanic mountain range that interrupts the coastal plain of the Gulf of Mexico (Geissert, 1999; Fig. 1). The current morphology of the area has been mostly shaped by Quaternary dynamics, going from an empty deep basin during times of sea-level low stands to a depositional coastal plain during times of sea-level high stands (Geissert, 1999; Kjerfve, 1994). The mountain ridge that connects La Mancha Hill with the adjacent western mountains divides La Mancha lagoon into two contrasting sub-basins (Fig. 1). Differences in freshwater input, marine influence, energy of the sedimentary environments, and human occupation have created two clearly distinct environments for mangrove forests, which today occupy $\sim 3.55 \mathrm{~km}^{2}$ around the lagoon"

\section{What was transect in Fig. 1 based on?}

The transect represented an arbitrary line that was drawn aiming to describe the morphology and likely evolution of the area. We have excluded the transect and replaced Fig. 1D.

\section{More detail is needed here about canals (referred to later) and the nature and extent of human impact.}

There was an idiomatic misunderstanding, we misused the word "canals" for referring to drainage channels. We have amended the text likewise. Also, we have reworded the last paragraph of Study Area, which now reads "Regional human occupation has been reported since at least $\sim 4,600 \mathrm{BP}$, and the lagoon has apparently been an important source of resources for human populations (Moreno-Casasola, 2006). This factor has exerted direct pressure on the mangrove forest through deforestation for timber and fuel wood extraction, and more recently in the interruption of surface and subsurface flows in the by infrastructure of the oil industry. These local factors have been especially harsh on the northern sub-basin, where only sparse remnants of the mangrove forest survive today. Thus, whereas vigorous mangrove forests surround the southern sub-basin, the northern sub-basin is occupied by highly disturbed vegetation including sparse mangrove remnants. Regionally, growing human population and the parallel development of infrastructure apply further pressures to coastal ecosystems through pollution, accelerated erosion, increasing sea level, among other elements (Gilman et al., 2008)."

\section{Methods. Were water depths measured when the surface sediment samples were taken? \\ Yes, we have added a bathymetric map of the lagoon.}


Did you measure LOI for these samples to look at spatial variability? Grain size? This information would give an idea of basin bathymetry. Presumably there would be a clear river channel?

We added analyses of TIC, TOC, and TN on surface samples and demonstrated that there are significant differences between the northern and southern sub-basins, providing further, more solid elements for interpreting the fossil record "TC content in modern samples varied between 3.1 and $12.3 \%$, with mean and median of 4.9 and $4.4 \%$, respectively. Although mean values for the northern and southern sub-basins were not statistically differentiable $(\mathrm{t}=1.66, \mathrm{p}$-value $=0.11)$, the northern sub-basin consistently showed lower values (Fig. 3). Differently, individual fractions of $\mathrm{C}$ resulted statistically differentiable, with a higher concentration of TOC in the southern sub-basin $(3.56, \mathrm{p}$-value $=0.002)$ and a higher concentration of TIC in the northern sub-basin $(\mathrm{t}=-2.47$, $\mathrm{p}$-value $=0.023)$. TN range between 0.02 and $0.37 \%$ with mean and median of 0.23 and $0.24 \%$, respectively (Fig. $3)$, with southern concentration statistically higher than the northern concentration $(t=5.54$, p-value $<0.001)$. TC resulted statistically associated with TN, TIC, and TOC, although the magnitude of the correlation was substantially higher with the latter (Fig. 3). Whereas TIC resulted moderately associated only with TN, TOC was strongly associated with both TC and TN (Fig. 3)."

\section{What evidence do you have to support claim of deep and bucket shape basin?}

Where it read "Thus, the lacustrine basin of La Mancha was probably deep and bucketshaped, impeding the establishment of mangrove forests", it now reads "Thus, the lacustrine basin of La Mancha was probably deeper than modern, impeding the establishment of mangrove forests".

Was anything else done on the core other than pollen? LOI? What were the shells, terrestrial? aquatic/ freshwater or marine? Do they tell you anything directly about salinity?

We have added TC and TN analyzed on modern and fossil samples, which greatly strengthened our interpretation. Biological indicators other than pollen provide a wealth of information on different environmental attributes. The goal of our research was reconstructing the evolution of the mangrove forest, which we did through the fossil pollen record, and the modern context provided by the spatial sampling. The shells we found were marine bivalves, and we then clarified in the discussion that their presence through the record evidences a constant marine influence through time. We added to the discussion "Additionally, the constant presence of marine shells through the sedimentary record (Fig. 2) demonstrates a permanent marine influence through the last $\sim 7,800$ year."

\section{Results. Radiocarbon dates - need to add calibrated dates to Table 1.} Calibrated dates were added to Table 1 .

\section{Why bulk dates? What was OM content? See query above re LOI.}

The material dated was bulk sediment since no other material such as macrofossils or charcoal could be found. We are aware of the possibility of a ${ }^{14} \mathrm{C}$ age offset but were not able to quantify this in the present study. We added TC and TN for the entire record, 
making evident that the content of TC of points sampled for radiocarbon analyses varied between 2 and $7 \%$. Although TC content is likely associated with the organic fraction, we did not quantify organic matter content for the fossil samples.

\section{Add actual dates to Fig 2.}

Actual dates are in Table 1, thus we considered it was not necessary repeating this information on Fig. 2 as the figure is already crowded.

What was/is human disturbance in $\mathbf{N}$ basin? When did it start? (see above). In the study area it now reads "Regional human occupation has been reported since at least $\sim 4,600 \mathrm{BP}$, and the lagoon has apparently been an important source of resources for human populations (Moreno-Casasola, 2006). This factor has exerted direct pressure on the mangrove forest through deforestation for timber and fuel wood extraction, and more recently in the interruption of surface and subsurface flows in the by infrastructure of the oil industry. These local factors have been especially harsh on the northern sub-basin, where only sparse remnants of the mangrove forest survive today. Thus, whereas vigorous mangrove forests surround the southern sub-basin, the northern sub-basin is occupied by highly disturbed vegetation including sparse mangrove remnants. Regionally, growing human population and the parallel development of infrastructure apply further pressures to coastal ecosystems through pollution, accelerated erosion, increasing sea level, among other elements (Gilman et al., 2008)."

Was NMDS run on core samples alone to improve discrimination between these? No; as stated in the text, NMDS was run on both modern and fossil samples as our interest was to investigate the establishment of modern systems in the area.

Discussion. More about the \% mangrove taxa in the surface sediment and core samples compared to modern \% vegetation cover would be useful.

We don't have reliable quantitative data on the forest surrounding La Mancha. We discuss mangrove representation in the first two paragraphs of the discussion, where we demonstrate that although mangrove taxa percentages are generally high, there is a clear distinction of percentages between the two sub-basins.

Base of core - sea water flooding - text indicates this recorded at 12-13m below modern surface. How far below modern was sea level 8 - $6 \mathrm{Ka}$ ? Is it $6 \mathrm{~m}$ (see bottom of p.23)? Is there any other evidence to support the idea of sea-water flooding and then a deep water body? (see above).

See level regional curves for the Gulf of Mexico and the Caribbean are shown in Fig. 7 (former Fig. 6), and their difference with sediment depth were used for estimating lagoon water depth. We explained better in the discussion that now reads "Through this time period, the mud-water interface was between 13 and $9 \mathrm{~m}$ below the modern surface, which today is at sea level. At the same time, average sea level was between 9 and $5 \mathrm{~m}$ below modern. The difference between mud-water interface depth and sea level can only be accounted by lagoon water depth, which was $~ 4$ m below sea level (Fig. 6A)."

On Fig. 6 do the depths on the y axis relate to both core depth and the height of sea level relative to modern? 
Fig. 7 (former Fig. 6) is meant to compare the depth and age scales of core depth and sea level, and thus they have to necessarily be the same. To avoid confusion, the y-axis label that read "Depth $(\mathrm{m})$ ", now reads "Depth (m below modern surface)".

6300-5400 Is there any clear evidence to support the claim of complete closure of the lagoon? Period of more silt deposition. Are these sediments more organic?

We tried to clarify through the manuscript that the establishment of mangroves (either true mangrove trees or marshland vegetation) requires depositional environments, which an open lagoon would not have provided given the high energy of direct sea influence. We hope to have strengthened our interpretation by adding the curves of TC and TN.

5400-3700 What's the real basis for identifying modern seasonal cycle?

This is just an interpretation based on the fact that sea level and sediment interface level apparently became similar. We explained better in the text that now reads "Whereas the rate of sea-level rise continued to decrease, relatively high sedimentation rates were evident in La Mancha sequence up to $\sim 5000$ cal BP, when apparently the rates of sediment deposition in the lagoon and those of sea level rise became similar (Fig. 6A). Such equilibrium between sediment deposition and sea-level rise implies the definition of a coastal erosive baseline that allowed the deposition of sand in the coast by the northerly currents during the dry season, creating the sandbar that dams the lagoon. Differently, during the wet season, the fluvial input would have the capacity to erode the sandbar, opening the direct contact between the lagoon and the sea and, thus, resulting in the modern seasonal flood cycle."

Last 3700 what's the balance between climate, sea level and human disturbance? See note above re what is known about disturbance?

I hope this question has been addressed by the multiple changes we made through the document. 
Holocene establishment of mangrove forests in the western coast of the Gulf of Mexico

2

3

Cordero-Oviedo, Cª, A. Correa-Metrio ${ }^{\text {b, }}$, L.E. Urrego ${ }^{c}$, G. Vázquez-Hurtado ${ }^{\mathrm{d}}, \mathrm{M}$.

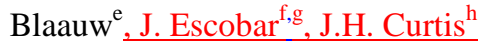

a Posgrado en Ciencias de la Tierra, Universidad Nacional Autónoma de México, Coyoacán, Ciudad de México, México 04510, ceciliacorderoviedo@ gmail.com, ${ }^{b}$ Instituto de Geología, Universidad Nacional Autónoma de México, Coyoacán, Ciudad de México, México 04510, acorrea@geologia.unam.mx, ${ }^{\mathrm{c}}$ Departamento de Ciencias Forestales, Universidad Nacional de Colombia, Sede Medellín A.A. 568 Medellín, Colombia, leurrego@unal.edu.co, ${ }^{\mathrm{d}}$ Instituto de Ecología, A.C. Carretera antigua a Coatepec 351, El Haya, Xalapa 91070, Veracruz, México, gabriela.vazquez@inecol.mx, ${ }^{\text {e }}$ School of Natural and Built Environment, Queen’s University Belfast, Belfast, United Kingdom, maarten.blaauw@qub.ac.edu, ${ }^{\stackrel{f}{ }}$ Departamento de Ingenieria Civil y Ambiental, Universidad del Norte, Km 5 Via Puerto Colombia, Colombia, jhescobar@uninorte.edu.co, ${ }^{\mathrm{g}}$ Center for Tropical Paleoecology and Archaeology, Smithsonian Tropical Research Institute, Box 0843-03092, Balboa, Panama, ${ }^{\text {h }}$ Department of Geological Sciences, University of Florida, Gainesville, FL, 32611, USA, curtisj@ufl.edu

*Corresponding autor: Alexander Correa-Metrio, acorrea@geologia.unam.mx

\section{Abstract}

The successful establishment of mangrove ecosystems depends on an intricate network of interactions among physical and biological factors that are highly dynamic through time. At millennial to centennial time scales, regional climates, sea levels, and local geomorphology 
play critical roles in the establishment of mangroves. Whereas fluvio-marine dynamics define coastal sedimentary settings, regional precipitation and freshwater input modulate salinity and seasonal flooding patterns. We analyzed a 7800-year-old, continuous sedimentary record from the western coast of the Gulf of Mexico to shed light on regional biophysical coastal processes and the history of the mangroves that occupy the region today. We used a systematic sampling of mud-water interface sediments to generate a modern reference frame for interpreting fossil pollen assemblages. Our results indicate that the cored location that is currently approximately at sea level, was under below sea level from $~ 7800$ to 4000 calibrated years before present (cal BP). The establishment of dense mangrove stands took place around $3700 \mathrm{cal} \mathrm{BP}_{2}$ when regional sea levels stabilized, $\underline{\text { resulting in a substantial increase of organic matter and therefore carbon stored in the }}$ sediments. However, the mangrove ecological succession that started at $\sim 6000 \mathrm{cal} \mathrm{BP}$ was interrupted by a regional drought that extended from $~ 5400$ to $3700 \mathrm{cal}$ BP. From $3700 \mathrm{cal}$ BP to Present, the lagoon has been characterized by relatively stable both substratum and sea level, that together have facilitated the establishment of mangrove forests. Overall, our record demonstrates the complexity of the interactions between local and regional factors in the development and evolution of both coastal geomorphology and ecosystems.

Keywords: coastal environment; Gulf of Mexico; Holocene; pollen analysismangroves; sea-level changes; pollen analysis

\section{Introduction}


Mangrove ecosystems are a large component of tropical and sub-tropical coastal

landscapes. Occupying intertidal zones (Lugo and Snedaker, 1974), they intermediate $\underline{\text { regulate the relationship between continental dischargesdischarge of sediments and water; }}$ mainly fluvial, and sea level (Ellison, 1989). The main engineers of these ecosystems are a reduced group of plant species physiologically adapted to brackish-to-saline substrates (Ball, 2002; Vovides et al., 2014). The establishment of mangrove forests creates the conditions for complex food webs that incorporate marine and continental components. The entire mangrove ecosystem is fundamental for providing products and ecological services, which reflectresulting in direct and indirect uses by human populations, mainly fuelwood, fisheries, sediment trapping, and carbon storage (Bouillon et al., 2008; Feller et al., 2017; Méndez et al., 2007; Ward et al., 2016).

Although they represent one of the most important carbon sinks worldwide (Bouillon et al., 2008), together with coral reefs and tropical forests, mangroves are among the most endangered modern ecosystems (Valiela et al., 2001). It has been estimated that through the last two decades of the 20th Century, $35 \%$ of the global mangrove area had been lost mostly because of direct and/or indirect anthropogenic causes (FAO, 2007). The main human-related causes of mangroves loss are the conversion to aquaculture and agriculture, urbanization, and pollution (Feller et al., 2017; Gilman et al., 2008; Thorhauga et al., 2017), which in Mexico have translated in a net loss $~ 240$ ha/year through the last decades (Hamilton and Cassey, 2016). The rapid rate at which these threats to mangrove ecosystems are growing highlights the need ef $\underline{\text { to }}$ understanding them in the context of their natural history and the intricate network of factors that interact to facilitate or impede their colonization and establishment. 

mangrove communities thrive and persist through time (Gilman et al., 2008). Healthy vigorous mangrove forests, and therefore ecosystems, depend on a delicate balance between marine influences and freshwater and sediment input from continental areas acting upon specific geomorphologic settings (Chapman, 1976; Lugo and Snedaker, 1974; Soares, 2009). Whereas marine influences on mangrove ecosystems materialize through tidal regimes and sea level changes that define basetevelline for erosion and accumulation of sediments, regional climates and vegetation cover over the mainland control continental discharge of freshwater and sediments along the coast. Thus, through the Holocene, changes in precipitation, vegetation cover, geomorphologic dynamics, and sea levels have probably led to high environmental variability over the intertidal areas (Geissert Kientz, 1999). In the Gulf of Mexico and the Caribbean, regional sea levels have progressively risen since the deglaciation (Milliken and Anderson, 2008; Toscano and Macintyre, 2003), whereas annual precipitation has shown a wide variability associated with extraterrestrial forcings (e.g. solar activity and orbital cycles, Haug et al. 2001, Hodell et al. 2001) and higher frequency processes associated with complex internal systems (e.g. El NiñoSouthern Oscillation, Moy et al. 2002). The balance between fluvial loads and sea-level rise modulates local geomorphologic and sedimentary processes, defining the formation of either depositional or erosional environments the balance of which balance is in turn critical for the establishment and persistence of mangroves (Parkinson et al., 1994). Indeed, modern net losses of mangrove cover have been widely associated with sea-level rises along unprotected coasts (Suárez et al., 2015). Thus, the definition of the context that led to the development of modern mangrove forests would provide important clues for identifying the limits of environmental pressure that these ecosystems can endure. 
the evolution of coastal landscapes through time. Understanding the natural development of mangrove ecosystems and the main factors involved in the process would give insights into the threat level that coastal zones face given modern environmental change (Lopez-Portillo et al., 2011; Thom, 1967). Here we use the pollen record of a 13-m-long 8,000-year-old sedimentary sequence retrieved from La Mancha Lagoon, State of Veracruz, Mexico, to reconstruct the history of the local vegetation through the Holocene. By analyzing the history of vegetation assemblages as reflected by fossil pollen spectra, we aim to answer the following questions: i) what has been the role of sea-level rise and precipitation variability through the Holocene in the establishment and persistence of mangrove forests in the west coastline of the Gulf of Mexico? ii) when did the barrier-lagoon systems of the region consolidate in the context of Holocene environmental variability?

\section{Study Area}

La Mancha lagoon is located in the State of Veracruz, Mexico, on the western coasts of the Gulf of Mexico (19.579 Nº $96.387 \mathrm{~W}^{\circ}$, Fig. 1). With a north-to-south length of $3 \mathrm{~km}$, the lagoon has an area of $\sim 1.35 \mathrm{~km}^{2}$ distributed in two sub-basins separated by a strait located around near the center of the water body (Fig. 1). Whereas the southern subbasin is exposed to permanent freshwater input from the Caño Grande River that drains water from a basin of almost $2,500 \mathrm{~km}^{2}$, the northern sub-basin more exposed to tidal influence through an ephemeral mouth that communicates seasonally with the sea seasonally(Fig.1) (Lankford, 1977; Moreno-Casasola, 2006). During the dry season, a sand bar accumulates closing the estuarine mouth and causing a damming of continental 
118 freshwater. With the onset of the rainy season, freshwater starts to accumulate, eventually

119 breaking the sandbar, opening the mouth, and creating a direct connection with the sea

120 (Moreno-Casasola, 2006). Thus, lagoon dynamics are intimately linked to regional climate

121 that is warm (temperatures from 22 to $26^{\circ} \mathrm{C}$ ), with an annual mean precipitation of 1222

$122 \mathrm{~mm}$, with $85 \%$ of the annual value falling between June and October (Fig. 1) (Servicio

123 Meteorologico Nacional, 2018). The dry season is especially pronounced between

124 December and April with mean monthly precipitations below $20 \mathrm{~mm}$, whereas-while

125 November and May are characterized by a mean precipitation around $50 \mathrm{~mm}$. By the end of

126 the summer and early autumn, the area is exposed to tropical cyclones, although their

127

128

129

130

incidence is relatively low compared with other areas of the Gulf of Mexico (MorenoCasasola, 2006).

$\underline{\text { La Mancha lagoon belongs to a geomorphic unit known as the Low Cumulative }}$ Plain that formed during the Quaternary (Geissert Kientz, 1999), allowing deposition of clayey-silt sediments. The lagoon formed at the margin of a volcanic mountain range that interrupts the coastal plain of the Gulf of Mexico (Geissert Kientz, 1999; Fig. 1). The current morphology of the area has been mostly shaped by Quaternary dynamics, going from an empty deep basin during times of sea-level low stands to a depositional coastal plain during times of sea-level high stands (Geissert Kientz, 1999; Kjerfve, 1994). The $\underline{\text { mountain ridge that connects La Mancha Hill with the adjacent western mountains divides }}$

La Mancha lagoon into two contrasting sub-basins (Fig. 1). The lageon formed at the margin of a voleanic mountain range that interrupts the coastal plain of the Gulf of Mexice (Geissert, 1999) (Fig. 1).Differences in freshwater input, marine influence, and energy of $\underline{\text { the sedimentary environments have created two clearly distinct environments for mangrove }}$ forests, which today occupy $\sim 3.55 \mathrm{~km}^{2}$ around the lagoon. 
143 tidal levels at $22 \mathrm{~cm}$ and $-30 \mathrm{~cm}$ from average sea level, respectively), preventing the

144

145

146

formation of tidal currents. This feature together with the permanent input of fresh water and the sheltering of the lagoon from the energy of the waves by La Mancha Hill (Fig. 1)

have probably played a critical role at in maintaining the morphology of the lagoon, avoiding the formation of tidal eeastsmudflats, marshes, and/or estuaries (Geissert Kientz, 1999). Through the lastOver recent decades, progressive loss of depth of the lagoon because of sediment accumulation suggests that sediment input surpasses local erosion (Matus-Moreno-Casasolaet at., 19942006), although this might not have been the case through the entire history of the area.

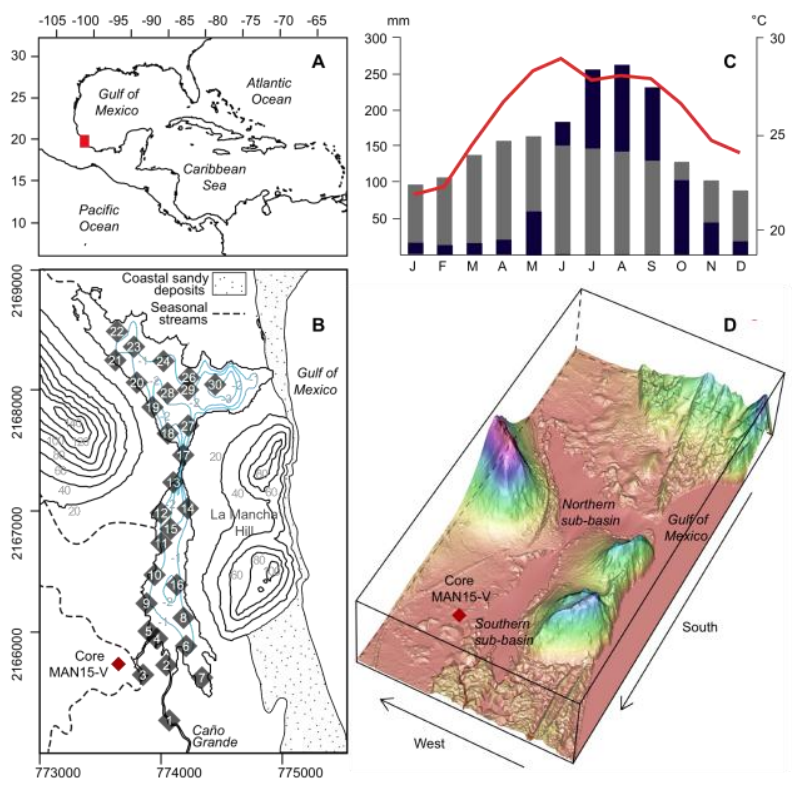

153 Figure 1. Study area. A. Location of La Mancha lagoon in the continental context. B.

154 Locations sampled for modern and fossil sediments in the local context of La Mancha 
coastal lagoon; elevation contours are shown in increments of $20 \mathrm{~m}$ asl (solid black lines), whereas a basic bathymetry based on field observations is shown as blue contours. C. Monthly precipitation (blue bars), evapotranspiration (gray bars), and monthly mean temperature (black line with dots) at La Mancha Meteorological Station (Servicio Meteorologico Nacional, 2018) D. Topographic profile throughrepresentation of La Mancha coastal lagoon.

(1)

Pollen assemblages contained in sediments reflect parental vegetation and are therefore useful for reconstructing environmental dynamics through time (e.g. CarrilloBastos et al., 2010; Urrego et al., 2009; Urrego et al., 2018). Given the regional geomorphology, the large size of the catchment basin of Caño Grande River, and the proximity to high mountain ranges, the pollen spectra of sediments from La Mancha lagoon might contains regional and local taxa (Moreno-Casasola, 2006; Travieso-Bello, 2000). Whereas the former are transported by water and wind currents, the latter are produced by in situ vegetation (Hooghiemstra et al., 2006). Regional elements come mostly from montane forests that dominate the regional highlands (Rzedowski, 2006Gareía France et al., 2008; Williams-Linera, 2002) and are characterized by wind-pollinated anemophyllous-taxa with long-distance pollen dispersal (e.g. Alnus, Myrica, Ulmaceae, Quercus, and Pinus), which in turn result tend to be overrepresented in the pollen spectra. From within these allochthonous elements, Pinus is worth noticing because of the opportunist nature of most of the parental species (Richardson, 1998), which results in a high representation of this taxon in pollen sepectra when environmental conditions are suboptimal for other arboreal elements (e.g. during drughts, Correa-Metrio et al., 2013). Local elements of the pollen spectra area in turn associated with two main vegetation types, namely lowland and 
mangrove forests. The hills that surround the lagoon reach heights up to $300 \mathrm{~m}$ asl and are mostly occupied by species of Desmodium, Inga, Machaerium, Psychotria, Protium,

Bursera, Moraceae-Urticaceae and Acacia. The salt marshes, coastal dunes, and beaches that characterize local cumulativeflood plains are mainly dominated by species of Cyperaceae, Amaranthaceae, Typha, Asteraceae, Chenopodiaceae, Mimosa and Croton.

These vegetation types can be associated with the distal part of a marine transgression plaine, or be related to the first stage of a progradational pattern indicative of a typical ecological succession on intertidal habitats (González and Dupont, 2009).

$$
\text { The edges of the lagoon are occupied by species typical of mangrove forests, }
$$

\section{Rhizophora mangle, Avicennia germinans, Conocarpus erectus and Laguncularia}

racemosa (Travieso-Bello, 2000 and Merene-Casasela, 2006). The interplay of these species is modulated by their differential adaptation to the changing environmental conditions along a salinity gradient, which in turn defines the structure and composition of the forest (Lugo and Snedaker, 1974; Travieso-Bello, 200; Urrego et al., 2009). Thus, these forests are highly sensitive to changes in sea-level, coastal progradation and/or erosion at different time scales (Ellison, 2008). Mangrove forest species are adapted to specific environmental conditions, with $R$. mangle tolerating high inundation levels, strong wave energy and shorter distances to the sea, A. germinans thriving in more saline environments, hurricane-disturbed or experiencing severe droughts, L. racemosa is being restricted to average minimum temperatures ef mere thanover $15.5^{\circ} \mathrm{C}$ and successional processes triggered by anthropogenic disturbance, and $C$. erectus being tolerant to higher sediment pH typical of supra-tidal waters close to well drained forests (González et al., 2010; Hogarth, 2007; Urrego et al., 2009; Urrego et al., 2010). 
Regional human occupation has been reported since at least $\sim 4,600 \mathrm{BP}$, and the

lagoon has apparently been an important source of resources for human populations

(Moreno-Casasola, 2006). This factor has exerted direct pressure on the mangrove forest $\underline{\text { through deforestation for timber and fuel wood extraction, and more recently in the }}$ interruption of surface and subsurface flows in the by infrastructure of the oil industry. These local factors have been especially harsh on the northern sub-basin, where only sparse remnants of the mangrove forest survive today. Thus, whereas vigorous mangrove forests surround the southern sub-basin, the northern sub-basin is occupied by highly disturbed vegetation including sparse mangrove remnants. Regionally, growing human population and the parallel development of infrastructure apply further pressures to coastal ecosystems $\underline{\text { through pollution, accelerated erosion, increasing sea level, among other elements (Gilman }}$ et al., 2008).

\section{Methods}

\subsection{Field work and laboratory analysis}

In autumn 2015, a 13-meter-long core was recovered from the southern part of La Mancha coastal lagoon (core MAN15V, Fig. 1), under an A. germinans stand, using a modified Livingston piston corer (Colinvaux et al., 1999). The core was longitudinally sectioned, stratigraphically described, and stored at $\sim 4^{\circ} \mathrm{C}$ to preserve the sedimentary evidence. The chronological control of the sedimentary sequence was based on eight accelerator-massspectrometer (AMS) radiocarbon dates of bulk sediment, homegenously distributed along the coregiven that no other material such as macrofossils or charcoal could be found. Radiocarbon dates were calibrated to years before present (hereafter cal BP) using the 
IntCal13 curve (Reimer et al., 2013), and calibrated dates were used to build a Bayesian age-depth model using Bacon (Blaauw and Christen, 2011). The core was subsampled every $\sim 12.5 \mathrm{~cm}$ for pollen analysis, aiming at a temporal resolution of $\sim 75$ years between contiguous samples. A total of 104 samples were processed for pollen analysis using standard pollen extraction techniques (Faegri and Iversen, 1989). Samples were analyzed under transmitted-light microscope at magnifications of $\mathrm{x} 400$ and $\mathrm{x} 1000$, aiming to $\underline{\text { reach a }}$ minimum pollen sum of 300 pollen grains. Grains of the family Cyperaceae and pteridophytes spores were excluded from the pollen sum, although they were counted and included in the interpretation. Pollen counts were transformed into percentages of the pollen sum and a stratigraphic pollen diagram was constructed.

Pollen taxa were classified into five groups according to their modern ecological affinities (ecological affinities after Lugo and Snedaker 1974, Ranwell 1972, Travieso-

Bello 2000): i) mangroves represented by Rhizophora mangle, Avicennia germinans, and Conocarpus erectus; although Laguncularia racemosa is an important component of the local mangrove forests, it was not found in the pollen spectra; ii) salt marsh vegetation represented by Cyperaceae, Amaranthaceae, Croton, Typha, Asteraceae, Chenopodiaceae, and Mimosa; ;ii) lowland forest represented by Inga, Acacia, Machaerium, Protium, Bursera, and Moraceae-Urticaceae; iv) montane regional forests represented by Alnus, Myrica, Ulmaceae, Quercus, and Miconia; and v) disturbance taxa represented by Pinus and Poaceae; these latter taxa were classified as representatives of disturbance because in Mexico they are distributed along environments unfavorable to vegetation development, usually associated with either natural or anthropogenic causes (Franco-Gaviria et al., 2018; Rzedowski, 2006). High abundances of Pinus pollen have been reported for areas submitted 
249 Metcalfe et al., 2000), mostly associated with early succession colonizers (Ramirez-Marcia

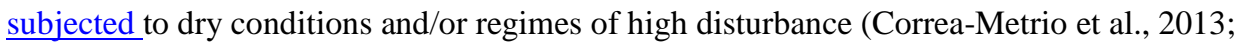
et al., 2001). Meanwhile, although Poaceae pollen is characteristic of successional processes of supratidal plains (Bush, 2002; Urrego et al., 2013), it is also found in pollen assemblages from all Mexican vegetation types, usually associated with disturbance (Correa-Metrio et al., 2013; Franco-Gaviria et al., 2018).

The fossil pollen record was complemented by sampling 30 locations homogeneously for modern mud-water interface (15 samples from each sub-basin) distributed along across the water body, using an Ekman dredge. This sampling was meant to cover the variability of the modern pollen spectra (Fig.1), especially the differences between depositional environments of the two sub-basins. Samples were treated and analyzed using the same techniques as the fossil samples.

Total both $\mathrm{C}(\% \mathrm{TC})$ and $\mathrm{N}(\% \mathrm{TN})$ were measured in fossil samples every $5 \mathrm{~cm}$ along the core and in modern samples. For this purpose, samples were freeze dried and crushed, and subsequently analyzed using a Carlo Erba NA1500 CNS elemental analyzer. Additionally, coulometric titration was used to determine carbonate carbon (\%TIC) in modern samples, allowing the estimation of organic carbon (\% TOC). The discrimination of $\underline{\text { TC into TIC and TOC in modern samples was used to infer the relationship between these }}$ two carbon sources in the system of La Mancha lagoon. 
A non-metric multidimensional scaling ordination (NMDS) was applied on pollen relative abundances, including both modern and fossil samples. The ordination was performed to summarize the temporal variability of the pollen spectra, and to evaluate vegetation temporal dynamics in the context of the modern lagoon. This technique ordinates samples on a $k$-dimensional space defined $a$ priori by the analyst, aiming to maintain the original topologic relationships among samples (Legendre and Legendre, 19982012). Although two-dimensional ordinations are readily used, we selected three dimensions to produce a relaxed ordination where the affinity among pollen spectra can manifest more freely. We used the Bray-Curtis metric to estimate dissimilarity among samples, a metric that relies more on compositional data than in on the abundance of individual taxa and has been proven monotonic to ecological distance (Faith et al., 1987).

\section{Modern samples were classified into southern and northern sub-basins as}

representative of dense and sparse mangrove forests, respectively. Whereas the northern sub-basin has direct contact with the sea through the ephemeral mouth, which creates a more energetic environment, and has been submitted subjected to important human disturbances and modifications resulting in sparse mangrove cover, the southern sub-basin is more influenced by the entrance of the river and is occupied by a well-developed dense mangrove stand. Thus, pollen spectra from these two sub-basins should reflect contrasting mangrove-forest cover conditions, and their relative oceanic and fluvial influences. The statistical significance of the difference between NMDS sample scores of the two subbasins were tested using a two-sample t-test (Zar, 1999). TIC, TOC, TC, and TN content in modern samples were compared using Pearson correlation coefficient, whereas $\underline{\text { comparisons of concentrations between the northern and southern sub-basins were also }}$ compared using two-sample t-test (Zar, 1999). 


\section{4. Results}

295

296

\subsection{Stratigraphy and chronology of the sedimentary record}

Sediments from the La Mancha coastal lagoon were mostly brownish, shelly clays with low content of organic material, and some intermissions of brownish silt with shell fragments and organic material (Fig. 2A). From the base of the core up to $1200 \mathrm{~cm}$ below lagoon floor (blf hereafter), the sediments were brown shellishshelly clay, while from 1200 to $663 \mathrm{~cm}$ blf the color turned into a light brown matrix (clay and silt) with shell fragments and carbonates. From 663 to $615 \mathrm{~cm}$ blf the elaylish-clayey sediments wasere brown with light brown bands. From 615 to $372 \mathrm{~cm}$ blf, the sediment showed brownish tones, and were mostly composed of clay with a thin layer of silt, shellish-shelly and little organic material. The uppermost $327 \mathrm{~cm}$ were dark to very light brown, with a uniform shellish-shelly clay composition (Fig 2A).

All radiocarbon dates resulted in stratigraphic order (Table 1). Although bulk $\underline{\text { sediment dates could lead to an }{ }^{14} \mathrm{C} \text { age offset, we were not able to quantify ot because of }}$ the lack of other quantifiable materials. Nevertheless, the high correspondence between TC and TN along the sedimentary record (Fig. 2) suggests that inorganic carbon represents a relatively low proportion of the sedimentary material. According to the age-depth model, the core has a basal age of $\sim 7840$ cal BP, resulting in an average sedimentation rate of 1.96 $\mathrm{mm} / \mathrm{yr}$ (Fig 2B). From the bottom of the sequence up to $5500 \mathrm{cal} \mathrm{BP}$, sedimentation rates were high, with maximum values around $5500 \mathrm{cal}$ BP $(4.10 \mathrm{~mm} / \mathrm{yr})$. From c. $5500 \mathrm{cal} \mathrm{BP}$ to present, sedimentation rates showed a decreasing trend, reaching $0.89 \mathrm{~mm} / \mathrm{yr}$ in the uppermost part of the core (Fig 2). 
317 Table 1. Radiocarbon dates of core MAN15V from La Mancha coastal lagoon. Depths in

318 cm below lagoon floor (blf). Ages calibrated after the IntCal13 curve (Reimer et al., 2013).

\begin{tabular}{lcccc}
\hline Laboratory code & Depth (cm blf) & ${ }^{14}$ C Age & Error & $\begin{array}{c}\text { Calibrated age } \\
(95 \% \text { range; cal BP })\end{array}$ \\
\hline UBA-34340 & 109 & 1290 & 24 & $\underline{1181-1283}$ \\
Beta-440367 & 175 & 1880 & 30 & $\underline{1730-1883}$ \\
UBA-34341 & 282 & 3447 & 26 & $\underline{3637-3826}$ \\
Beta-440368 & 373 & 3970 & 30 & $\underline{4300-4523}$ \\
UBA-34342 & 564 & 4732 & 41 & $\underline{5326-5584}$ \\
Beta-437078 & 649 & 4770 & 30 & $\underline{5334-5588}$ \\
UBA-34343 & 979 & 5624 & 41 & $\underline{6312-6482}$ \\
Beta-437079 & 1249 & 6700 & 30 & $\underline{7508-7616}$ \\
\hline
\end{tabular}

319

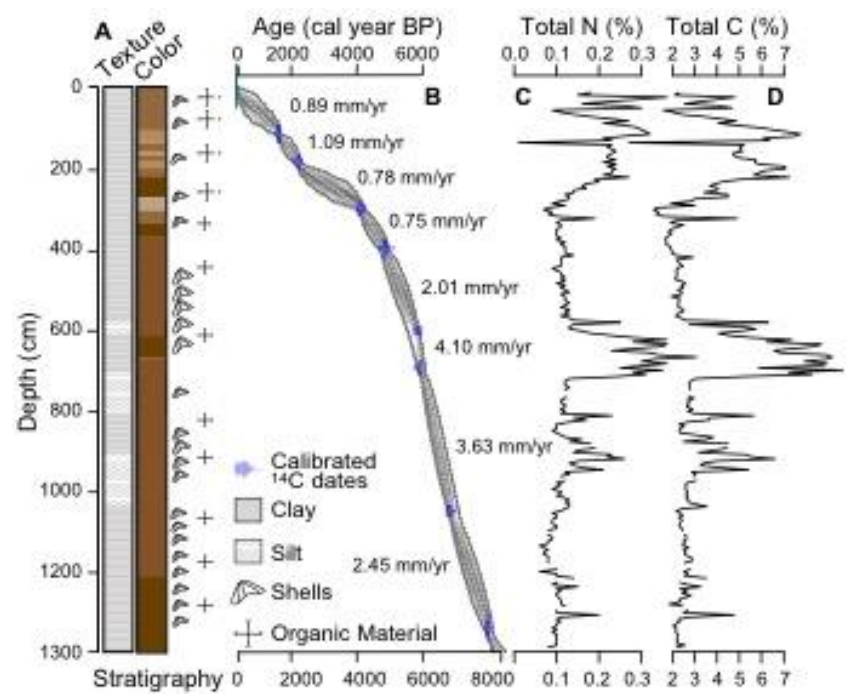


Figure 2. Core MAN15V from La Mancha coastal lagoon. A. Stratigraphy of the sedimentary sequence;: texture (left)-and, color (right), and organic and shell content. B. Age-depth model; calibrated ages (blue silhouettes), 95\% confidence intervals in grey (darker colors indicate higher probability), and sedimentation rates (mm/yr). C and D. Percentage of total nitrogen and total carbon content (TN and TC, respectively).

\subsection{Modern p Pollen spectra and $C$ and $N$ in modern samples}

Modern samples were characterized by 49 taxa, 18 and 31 identified at family and genus levels, respectively. Pollen sums varied between 300 and 387, whereas pollen counts including Cyperaceae and pterodophytes were between 322 and 472 palynomorphs.

Rhizophora, Cyperaceae, Moraceae-Urticaceae, Quercus, Pinus, and Poaceae dominated these samples (up to 45\%), whereas taxa such as Typha, Mimosa, Desmodium, Inga, and Ulmaceae were poorly represented (less than 5\%). One sample from the northern sub-basin resulted-was barren of pollen (sample 26, Fig. 1).

Avicennia and Rhizophora showed high percentages (up to 5 and $45 \%$, respectively) towards the southern sub-basin of the lagoon (Figs. 1 and 3). Contrastingly, other taxa such as Quercus, Myrica, and Pinus decreased southwards. Compositional differences between the northern and southern sub-basins of the lagoon were also evidenced-indicated by taxa that occurred only at the latter, such as Desmodium, Inga, and Protium (Figs. 1 and 3). Samples from the middle area of the lagoon (samples 12,13,14,17 and 18) (Figs. 1 and 3) contained the highest percentages of Cyperaceae and Moraceae-Urticaceae $(25 \%$ and $30 \%$, respectively), and minima of Typha, Asteraceae, and Psychotria. In the northern sub-basin 

above $10 \%$.

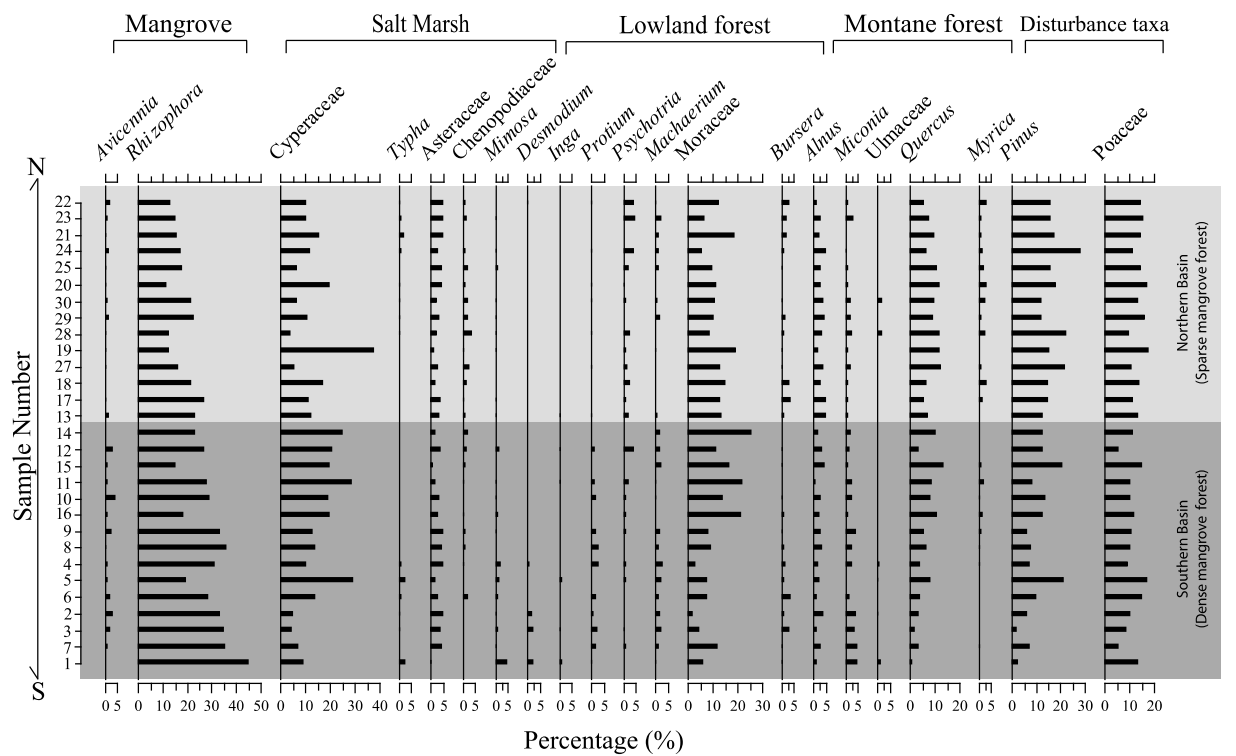

349 Figure 3. Pollen diagram of selected taxa from mud-water interface samples from La

350 Mancha coastal lagoon. Ecological affinities after Lugo and Snedaker (1974), Ramwell

351

(1972), and Travieso-Bello (2000). Samples are ordered from South to North with samples from the southern (northern) sub-basin highlighted in dark (light) grey.

TC content in modern samples varied between 3.1 and $12.3 \%$, with mean and median of 4.9 and $4.4 \%$, respectively. Although mean values for the northern and southern sub-basins $\underline{\text { were not statistically differentiable }(t=1.66, p \text {-value }=0.11) \text {, the northern sub-basin }}$ consistently showed lower values (Fig. 3). Differently, individual fractions of C resulted 
$\underline{\text { statistically differentiable, with a higher concentration of TOC in the southern sub-basin }}$ (3.56, $\mathrm{p}$-value $=0.002)$ and a higher concentration of TIC in the northern sub-basin $(\mathrm{t}=-$ 2.47, p-value $=0.023)$. TN range between 0.02 and $0.37 \%$ with mean and median of 0.23 and $0.24 \%$, respectively (Fig. 3), with higher mean concentration in the southern subbasin $\underline{(\mathrm{t}=5.54, \mathrm{p} \text {-value }<0.001)}$. TC resulted statistically associated with TN, TIC, and TOC, although the magnitude of the correlation was substantially higher with the latter (Fig. 3). Whereas TIC resulted moderately associated only with TN, TOC was strongly associated with both TC and TN (Fig. 3).

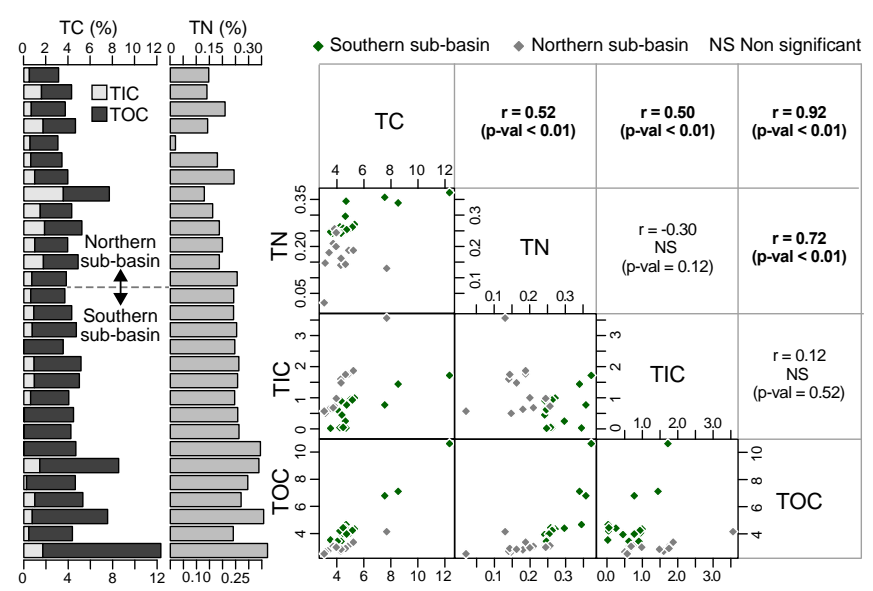

Figure 4. Content (\%) of carbon and nitrogen in the modern samples of La Mancha coastal $\underline{\text { lagoon. Total } \mathrm{C} \text { content (TC) discriminated into inorganic and organic fractions (TIC and }}$ TOC), and total N content (TN). Comparisons among sedimentary attributes are shown in the right side panels (biplots and correlation coefficients with their significance). 
Fossil pollen types included 55 taxa classified into 24 families and 31 genera. Pollen sums varied between 300 and 349 grains per sample (average 306 grains), whereas pollen counts that included Cyperaceae and pterodophytes reached between 303 and 359 palynomorphs per sample (average 317). The highest abundances were shown by Rhizophora, MoraceaeUrticaceae, Quercus and Pinus, while the lowest abundances were shown by Conocarpus, Inga, Bursera and Miconia. From within the 55 identified taxa, only Rhizophora, Cyperaceae, Typha, Asteraceae, Chenopodiaceae, Moraceae-Urticaceae, Alnus, Quercus, Pinus, and Poaceae persisted throughout the entire record. The record was discretized into four main pollen zones (Fig. 4) to facilitate the description of the sedimentary sequence. Pollen zones were defined based on an inspection of the distribution of pollen percentages though time, aiming to identify time periods characterized by relatively stable pollen assemblages.

\section{Pollen Zone I (from 1300 to 907 cm blf, c. 7840-6300 cal BP): The sediment showed TC} concentrations between 1.84 and $4.78 \%$, with mean of $2.54 \%$, and TN concentrations between 0.06 and $0.20 \%$, with mean $0.10 \%$ (Fig. 2). This zone showed high percentages of Rhizophora (up to 20\%), Moraceae-Urticaceae (up to 50\%), Quercus (up to 20\%), Pinus (up to 50\%), and Poaceae (up to 20\%). Low percentages (less than 5\%) were shown by Avicennia, Amaranthaceae, Croton, Typha, Asteraceae, Chenopodiaceae, Mimosa, Inga, Acacia, Machaerium, Protium, Bursera, Ulmaceae and Miconia (Fig.4). 
Pollen Zone II (from 907 to 569 cm blf, c. 6300 - 5400 cal BP): $\underline{\text { The sediment showed }}$ highly variable concentrations of both TC and TN (Fig. 2). TC varied between 2.28 and $9.67 \%$ with mean of $4.6 \%$, whereas TN varied between 0.09 and 0.43 with a mean of 0.19\%. This zone was dominated by Cyperaceae (20\%), Croton (10\%), Typha (20\%), Chenopodiaceae (15\%), Moraceae-Urticaceae (50\%), Alnus ( 6\%), Ulmaceae (10\%), Quercus (20\%), Pinus (50\%) and Poaceae (20\%). Percentages below 5\% were shown by Avicennia, Conocarpus, Amaranthaceae, Asteraceae, Mimosa, Inga, Machaerium, Protium, Bursera and Miconia with less than 5\%. The upper part of the zone was characterized by relatively low percentages of Pinus $(\sim 18 \%)$ and a substantial increase of Amaranthaceae, Croton, Typha, Asteraceae, Chenopodiaceae, and Cyperaceae (up to 20\%) (Fig. 4).

Pollen Zone III (from 569 to 280 cm blf, c. 5400 - 3700 cal BP): With lower variability, both TC and TN decreased substantially (Fig. 2). TC varied from 1.14 and $6.31 \%$ with mean of 2.45 , and $\mathrm{TN}$ varied between 0.07 and $0.25 \%$ with mean of $0.12 \%$. From $5400 \mathrm{BP}$ Rhizophora abundances began to increase gradually, and Avicennia showed-was less than 5\%. Pinus reached the highest abundances throughout the record (up to 60\%), while Amaranthaceae, Croton, Mimosa, Inga, Machaerium, Bursera, Alnus, Ulmaceae, Moraceae-Urticaceae, and Miconia showed their lowest percentages. Lastly, Typha, Asteraceae, and Chenopodiaceae showed abundances around 10\% (Fig 4).

\section{Pollen Zone IV (from 280 to 0 cm blf, c. 3700 cal BP - Present): TC and TN} progressively reached high variable concentrations (Fig. 2). TC varied between 0.02 and $7.77 \%$ with mean of $4.45 \%$, and TN varied between 0.01 and $0.36 \%$ with mean of $0.20 \%$. Abundances of Rhizophora and Avicennia reached their highest values (up to $60 \%$ and $10 \%$ 
respectively), and displayed an increasing trend towards the present. Amaranthaceae,

Croton, Typha, Chenopodiaceae, Myrica, Ulmaceae, Quercus, and Pinus abundances decrease up to the present. Meanwhile Acacia, Inga, Machaerium, and Protium presented their highest abundances (up to 10\%) (Fig. 4).

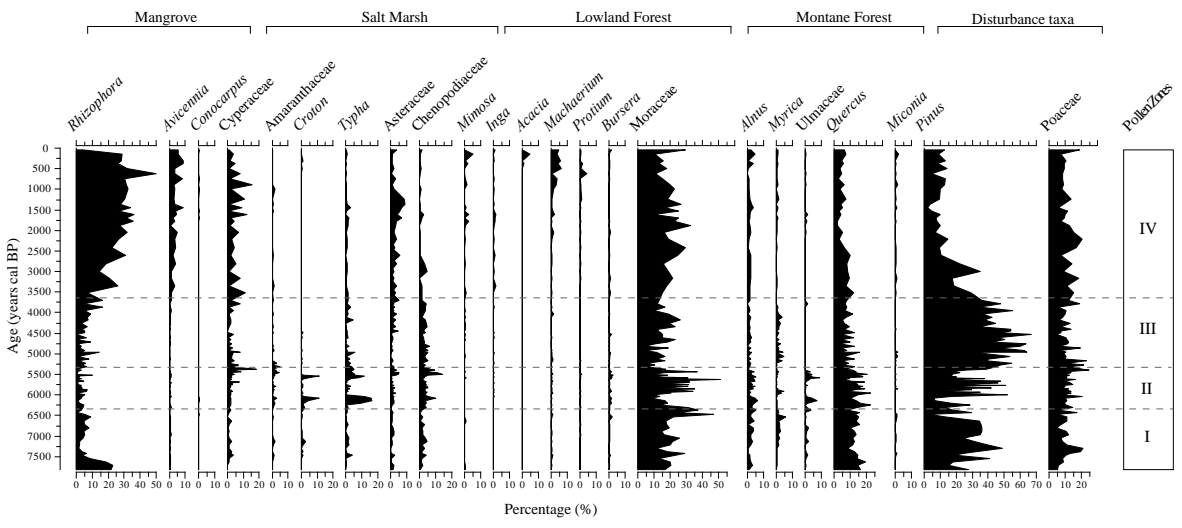

Figure $4 \underline{5}$. Fossil pollen diagram of selected taxa of core MAN15V from La Mancha coastal lagoon. (ecological affinities after Lugo and Snedaker 1974, Ramwell 1972, and Travieso-Bello 2000, and Castillo-Campes 2006).

\subsection{Statistical analyses}

The three-dimensional ordination of the modern and fossil pollen samples showed a stress of 0.144. Negative scores along Axis 1 characterized modern samples, whereas fossil samples were clearly divided into positive (negative) scores for samples older (younger) than 5400 cal BP (Fig. 5 and 6.B). Along Axis 2, both modern and fossil samples were mostly located between -0.31 and 0.2 , although fossil samples showed positive and 
negative excursions (Fig. 5). NMDS Axis 3 was characterized by widespread scores for

fossil samples and almost exclusively negative scores for modern samples (Appendix 1). southern sub-basins yielded significant differences in terms of Axis 1 and 2, but nonsignificant for Axis 3 (Table 2). Given the relatively flat behavior of Axis 2 and the lack of significance of Axis 3 (Appendix 1), only the first axis of the ordination will be considered

441 for interpretations hereafter.

442

Table 2. Comparison of NMDS sample scores in the three axes for modern samples from the northern and southern sub-basins, i.e scores from dense (D) vs. sparse (S) mangrove areas. For the comparison of scores along each axis, $t$ scores, degrees of freedom corrected 446 for variance differences between samples (d.f.), and p-value are shown.

447

\begin{tabular}{llll}
\hline Comparison & $\mathrm{t}$ & d.f. & p-value
\end{tabular}

Axis $1_{\mathrm{D}}-$ Axis $1_{\mathrm{S}} \quad-3.5184 \quad 18 \quad 0.0026$

Axis $2_{D}-$ Axis $2_{S} \quad-2.7661 \quad 26 \quad 0.0103$

Axis $3_{\mathrm{D}}-$ Axis $3_{\mathrm{S}} \quad 1.3831 \quad 24 \quad 0.1796$ 


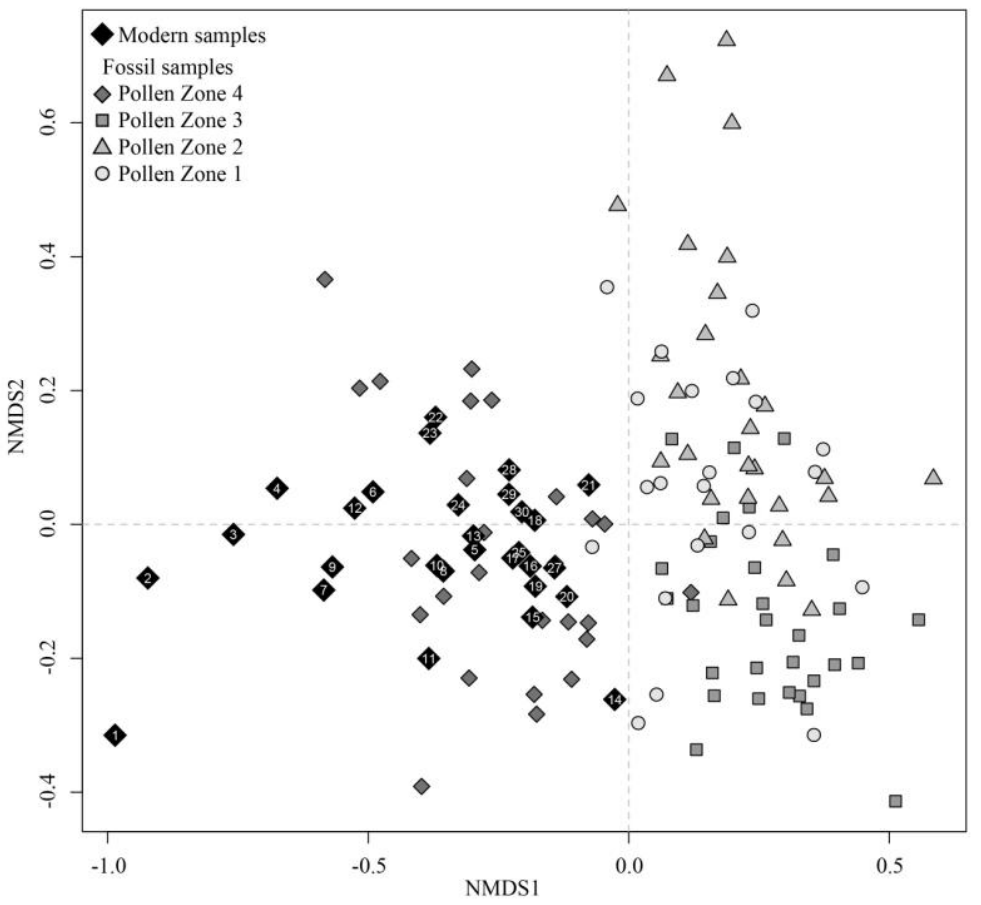

450 Figure 5ㅁ. Non-metric multidimensional scaling for modern and fossil pollen assemblages

451 from La Mancha lagoon. Modern samples in black diamonds showing sample number,

452 whereas fossil samples were symbol coded according to the declared legend.

\section{Discussion}

455

456

\subsection{Modern pollen spectrasediments of La Mancha coastal lagoon}

Palynological composition of modern samples generally reflected the patterns of modern vegetation, incorporating vegetation elements from the surrounding mangroves and salt marshes (local vegetation), and nearby lowlands and highland forest (regional vegetation).

Although the mangroves of La Mancha are dominated by A. germinans over R. mangle (Moreno-Casasola, 2006), modern pollen spectra were dominated by the latter (Fig. 3). 
Given its pollination mechanism, $R$. mangle produces high amounts of pollen, dominating most of pollen spectra from mangrove forests. Contrastingly, A. germinans is an insectpollinated species that produces low amounts of pollen (Hogarth, 2007), resulting in underrepresentation of the parental taxon in the pollen spectra where percentages as low as $5 \%$ implying an important share in the standing vegetation. However, the mean representation of $R$. mangle in modern samples from the densely mangrove-forested southern sub-basin $(\sim 25 \%)$ are low as compared to pollen spectra from stands dominated by this species which have been reported as high as $65 \%$ (e.g. Behling et al., 2001; Urrego et al., 2009). Although C. erecta and L. racemosa are components of the standing forest of La Mancha, they are not represented in the modern pollen spectra probably because of their low production, and also because of their distal position with respect to the sampled water body (Fovilla and De la Lanza, 1999Moreno-Casasola, 2006).

At In the southern sub-basin of La Mancha, the high percentages of Rhizophora reflect the relatively good conservation statge of the mangroves (Moreno-Casasola, 2006), with the exclusive presence of taxa such as Desmodium, Inga and Protium indicating a well preservation ofed lowland vegetation as well (Franco-Gaviria et al., 2018). Pollen spectra from the northern sub-basin contained lower percentages of Rhizophora, and a substantial representation of regional pollen, possibly coming from the highlands of the catchment basin. Through the lastover recent decades, the deleterious effects of human activities on mangrove cover have been more intense around the northern sub-basin of La Mancha lagoon (Lopez-Portillo et al., 2011; Moreno-Casasola, 2006), reflecting on pollen assemblages where the regional and disturbance elements are better represented (mainly Moraceae-Urticaceae, Myrica, Pinus, Poaceae, and Quercus) (Correa-Metrio et al., 2011; 
Franco-Gaviria et al., 2018). Although Rhizophora, Moraceae-Urticaceae, Pinus, and

Quercus do not dominate the shore vegetation of the most disturbed northern areas, they are represented by pollen percentages above $10 \%$ each (Fig. 3), reflecting the sparse nature of mangrove forests over this area. This finding reflects the widely reported overrepresentation of these taxa in pollen spectra, derived from their high production of pollen and their long-distance pollen dispersal capacity, as reported for species of anemophyllous pollination (e.g. Correa-Metrio et al., 2013; Ellison, 2008; Hooghiemstra et al., 2006; Marchant et al., 2002).

Modern samples resulted were clustered in the NMDS (Fig. 5), implying more consistency among the modern pollen spectra than between modern and fossil samples. This finding demonstrates that the modern heterogeneity of the lagoon does not represent the ecological and environmental variability of the area over the last $\sim 7800$ years.

Statistically significant differences between the NMDS Axis 1 scores of pollen assemblages from the two sub-basins demonstrate that density of mangrove forest cover can be identified though their pollen spectra. Overall, these findings imply $\underline{\text { indicate }}$ that i) pollen assemblages of La Mancha lagoon are systematically associated with physical and biological attributes of the region at a broad scale (regional vegetation), and ii) pollen spectra are highly sensitive to the modern environmental variability that express-throughout La Mancha lagoon (local vegetation). Thus, as reported for other areas (e.g. Franco-Gaviria et al., 2018; Urrego et al., 2009; Urrego et al., 2010), modern pollen assemblages of our studied lagoon provide a robust framework for interpreting our fossil pollen sequence.

Higher concentrations of TOC and TN in the southern sub-basin were probably a result of differences in surrounding vegetation and energy of the depositional environment. 
More vigorous vegetation in the southern sub-basin would produce higher amounts of organic matter rich in TOC and TN, whereas the lower energy of the depositional environment would prevent resuspension and, therefore, further oxidation of the sediments $\underline{\text { (Meyers, 1997). Differently, TIC resulted higher in the northern sub-basin, probably }}$ reflecting both higher contribution of marine particulate suspended matter and more oxidation of organic components (Bouillon et al., 2003). Overall, C and N analyses are consistent with higher organic matter storage in the sediments of the lagoon where mangrove forests are well preserved. The relationships that were found between the different components of $\mathrm{C}$ and $\mathrm{N}$ demonstrate that in the modern setting of La Mancha, $\underline{\text { TOC is the main component of TC. Although these relationships cannot be extrapolated to }}$ the fossil record, they demonstrate that $\mathrm{TN}$ is a good proxy for organic matter, and

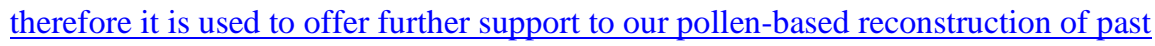
$\underline{\text { environmental dynamics. }}$

\subsection{Vegetation history of La Mancha Lagoon}

The pollen record of La Mancha lagoon reflects the complexities associated with the multiple factors that have intervened in the development toward the modern biotic and abiotic systems. Whereas highly variable abundances of regional vegetation suggest variability in freshwater input by precipitation and tributaries to the lagoon system, pollen from mangroves together with herbaceous vegetation offer insights into the successional patterns and development of the local vegetation (Urrego et al., 2013; Urrego et al., 2018). Additionally, the constant presence of marine shells through the sedimentary record (Fig. 2) demonstrates a permanent marine influence through the last $\sim, 800$ year. Together, these 
indicators illustrate the intimate interaction between sea levels and regional fresh water inputs (precipitation, sediments) that ultimately regulates the colonization, establishment, and development of mangrove ecosystems in the area. According to our pollen and geochemical data, the history of the vegetation that surrounds the lagoon and therefore the regional environmental history could be summarized in four main stages that will be discussed below.

From c.7800 to 6300 cal BP: sea-water flooding of valleys

\section{Through this time period, the mud-water interface was between 13 and $9 \mathrm{~m}$ below the} modern surface, which today is at sea level. At the same time, average sea level was between 9 and $5 \mathrm{~m}$ below modern. The difference between mud-water interface depth and sea level can only be accounted by lagoon water depth, which The comparison of our agedepth model with the reported increase of regional sea levels suggests that throughout this time period the mud water interface-was around $6 \simeq \underline{4} \mathrm{~m}$ below sea level (Fig. $6 \mathrm{~A})$. La Mancha Hill, an andesitic rock of Neogene origin (García-GilMoreno-Casasola, 2006; Geissert Kientz, 1999) (Fig. 1), probably acted as a barrier that protected the depositional environment from the erosive energy of the waves and winds. Through this period, even though sedimentation rates at La Mancha ( 3.04 mm/year) were lower than the inferred rate of sea-level increase, they are among the highest through the record. High rates of both regional sea-level rise and sedimentation at La Mancha are likely a result of the regional geologic instability that characterized the conformation processes-of the modern Gulf of Mexico in its final stages, up to 5000 cal BP (Davis, 2011; Pirazzoli, 1990). As sea level increased through the deglaciation and the early Holocene, sea-water flooded coastal plains and valleys at a speed that surpassed the accumulation of continental sediments. Thus, the 
lacustrine basin of La Mancha was probably deeper than modern-and bucket shaped, impeding the establishment of mangrove forests (Fig. 6C). A peak of Rhizophora from the bottom of the record to $\sim 7500$ cal BP (Fig. 4) probably shows the colonization of mangroves during the initial stages of the lagoon and the sea-water flooding, which were subsequently displaced by the formation of a deep-water body.

In México, Pinus populations thrive under early post-disturbance successional stages, or under conditions that are not optimal for other taxa (Metcalfe et al., 2000;

Ramirez-Marcial et al., 2001). Thus, the persistence of Pinus in high percentages from the bottom of the record to $\sim 6500 \mathrm{cal} \mathrm{BP}$ (Fig. 5) indicates that regional conditions were likely dry, an interpretation that is further supported by the lowest concentrations of TN (Fig. 7) and therefore of organic matter. These dry conditions probably played a central role at maintaining sedimentation rates that did not offset sea-level rise, impeding the establishment of mangrove forests, as demonstrated by the NMDS Axis 1 scores that were outside the envelope defined by modern samples (Fig. 6B $\underline{7 \mathrm{C}}$ ). 


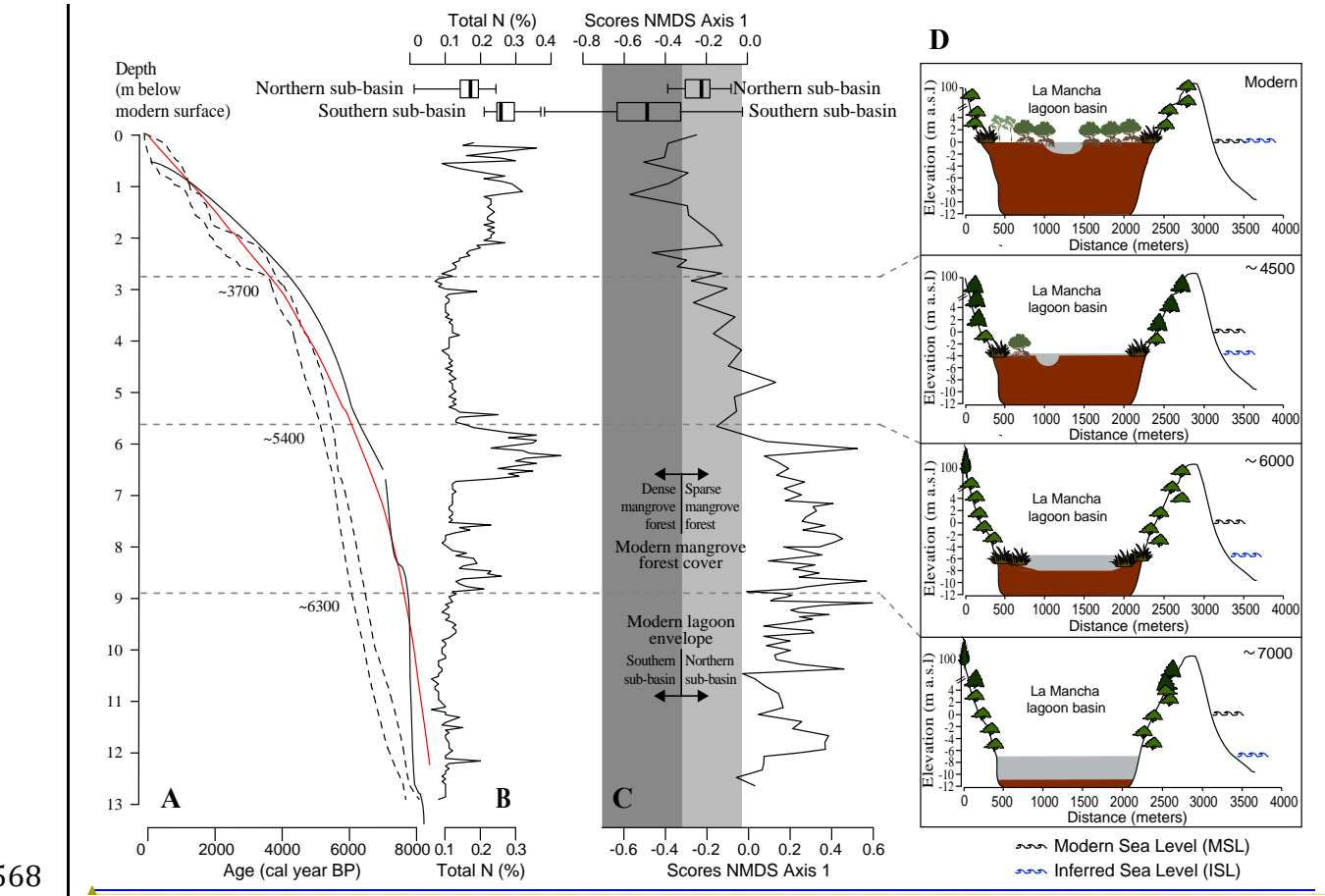

Figure 67. Environmental history of La Mancha Lagoon through the last 7,800 years. A. Age-depth model of core MAN15V from La Mancha Lagoon (dashed lines show 95\% confidence interval), compared with sea level rise curves for the Caribbean (red line, Toscano and Macintyre, 2003) and the northern Gulf of Mexico (black solid line, Milliken and Anderson, 2008). B. Sedimentary total nitrogen content (\%); boxplots illustrate total nitrogen in modern samples form the northern (up) and southern (down) sub-basins of the lagoon (whiskers show minimum and maximum scores). C. NMDS Axis 1 scores through time; boxplots illustrate scores of modern samples form the northern (up) and southern (down) sub basins of the lagoon (whiskers show minimum and maximum scores); scores of the modern environmental envelope represented by modern samples are highlighted in grey; scores of the interquartile range of samples from the well preserved southern sub- 
basin are in dark grey. $\mathbf{E D}$. Schematic development of La Mancha Lagoon, illustrated at 7,000, 6000, 4,500 cal BP, and Modern.

\section{From c. 6300 to 5400 cal BP: development of lagoon shores}

Whereas the rate of sea-level rise started to decline through this period, sedimentation rates at La Mancha remained high (3.86 mm/yr, Fig. 6). This phenomenon could be explained by two critical factors: i) following the reported deceleration of sea-level rise at $\sim 7000$ cal BP (Toscano and Macintyre, 2003), sand bars started accumulating at the mouth of coastal lagoons (Davis, 2011), providing a more stable plain for sediment accumulation at La Mancha; and ii) a substantial decrease in the percentages of Pinus, and an increase of montane forest taxa (e.g. Alnus, Quercus, and Ulmaceae) indicate wetter conditions that would be in turn associated with higher river sediment discharge. These regional wetter conditions could be related to the final stages of the Holocene Thermal Maximum, which was in general characterized by higher than present precipitation and temperature in the Northern Hemisphere (Renssen et al., 2009).

The lagoon became shallower, and the development of muddy shores is evidenced by high percentages of salt marsh vegetation (Fig. 5), and high accumulation of organic matter revealed by the increasing TN (Fig. 7B). This state of local vegetation and the high accumulation of organic matter suggest, a process also favored by the slowing rates of sea level rise (Fig. 6A), with dominance of pollen spectra by salt marsh taxa indicating also more tidal influence (González et al., 2010; Ranwell, 1972). Tthe closing of the ephemeral 
602

603

604

605

606

607

608

609

610

611

612

613

614

615

616

617

618

619

620

621

622

623

624

mouth ${ }_{2}$ sas-probably caused by lower energy associated with the shallowing of the lagoon, together with the intensification of the wind currents, and sea level changes reported for the Gulf of Mexico and the Caribbean (Balsille and Donoghue, 2004; González and Dupont, 2009; Urrego et al., 2013; Wooller et al., 2007). Pollen spectra suggest the early stages of a successional pattern of mangrove vegetation associated with the marine transgression, although NMDS Axis 1 sample scores demonstrate that mangrove forests were not established yet near the location where the core was retrieved.

\section{From c. 5400 to 3700 BP: A regional drought}

Whereas the rate of sea-level rise continued to decrease, relatively high sedimentation rates were evident in La Mancha sequence up to $~ 5000$ cal BP, when apparently the rates depesition-of sediments deposition in the lagoon and those of sea level rise became similar (Fig. 6A). Such equilibrium between sediment deposition and sea-level rise implies the definition of a coastal erosive baseline that, -allowed the deposition of sand in the coast by $\underline{\text { the northerly currents during the dry season, creating the sandbar that dams the lagoon. }}$ Differently, during the wet season, the fluvial input would have the capacity to erode the

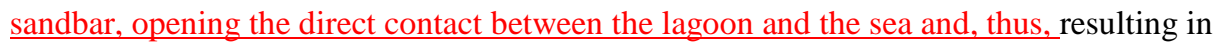
the modern seasonal flood cycle-of the lagøen. During the dry season, the coastal bar would be closed by the action of the waves and the prevailing winds, whereas during the rainy season the bar would be opened by the energy of the fresh water discharge. The lagoon thus became a shallow water body $\left(\mathrm{z}_{\max } \sim 1 \mathrm{~m}\right)$ mostly protected from the energy of the waves by La Mancha hill (Fig.1), and subjected to seasonal tidal and climatic fluctuations. From c. 5400 to $3700 \mathrm{cal} \mathrm{BP}$, the recurrent drainage of fresh water into the sea probably created a series of eanals channels giving the lagoon a physiography very similar 
to modern. However, according to the NMDS scores, vegetation at that time resembled the

626

627 northern sub-basin today (Fig. 6B), an area characterized by poorly developed sparse mangrove stands. Thus, vegetation assemblages from this period were a result of suboptimal environmental conditions for mangrove forest development. High percentages of Pinus (up to 60\%) through this period suggest that there was a regional drought in place, which likely maintained high substrate salinity by reducing freshwater river discharge to the lagoon. Thus, local vegetation consisted of a mixture of sparse mangrove trees with some salt marshes species, and a slow increase of mangrove pollen because of the prevailing dry conditions (Fig. 4). Although anthropogenic influence cannot be discarded as a plausible explanation for the sparse mangrove vegetation, the inference of a regional drought is supported by similar reports from Lake Petén Itzá between 4500 up to 3000 cal BP, Lake Tzib (Quintana Roo) at 3500 cal BP (Carrillo-Bastos et al., 2010; Mueller et al., 2010), and also in the Cariaco Basin record, with a trend from 5400 up to the present (Haug et al., 2001). Furthermore, the abrupt decrease of TN and its linear trend towards even lower concentrations (Fig. 7B) evidence rather oxidizing conditions, an environmental process that is difficult to explain from the perspective of human occupation.

\section{From c. 3700 cal BP to Present: the establishment of modern mangrove forests}

Mangrove pollen taxa showed the highest percentages_(Fig. 5), which-reflecteding an environment of relative stability where the exchange of saline and fresh water, and the input of sediments were balanced, producing an increase of mangrove forest biomass (Krauss et al., 2008). These conditions provided consolidated clay sediments, where as indicated by the NMDS scores, mangrove forests developed into mature forest stands of Rhizophora and Avicennia. Increasing concentrations of TN (Fig. 7B) indicate high 
accumulation of organic matter probably associated with the establishment of the mangrove forest (Bouillon et al. 2003). Sea level continued to increase at slower rates (Balsille and Donoghue, 2004) that were matched by the rate of sediment accumulation in La Mancha ( $\sim 0.92 \mathrm{~mm} / \mathrm{yr}$ on average). These more stable conditions for coastal ecosystems have been reported for other localities in the Caribbean coinciding with other records (Urrego et al., 2013), where mangrove forests developed under a relatively stable sedimentation rate (1.09 to $0.89 \mathrm{~mm} / \mathrm{yr})$.

Pinus and salt marsh pollen in La Mancha showed substantial decreases caused by wetter conditions and higher representation of local mangrove pollen, implying a lower regional influence on pollen spectra, and the continuation of the successional processes that led to the establishment of the mangrove forest (González and Dupont, 2009). At this stage, the lagoon seems to have reached its modern configuration, with influences from local processes like the annual opening of the ephemeral mouth, fluctuating floods of salt water, input of fresh water from the streams, and anthropogenic activities (Moreno-Casasola, 2006). Indeed, the sharp decrease of Rhizophora is likely reflecting the terrestrialization of the cored site, which today is occupied by an Avicennia germinans forest that floods only when the ephemeral mouth is closed and the lagoon reaches its maximum water level through the year. This latter observation is further supported by the high variability of TN concentrations towards the top of the record.

\section{Conclusion}

The sedimentary record of La Mancha lagoon encompasses the history of the-local and regional environmental conditions through the last $\sim 8,000$ years, including the 
673 the regional context under which the coastal lagoon formed, showing the transformation of

establishment of modern mangrove forest along the coast of Veracruz. The record shows the lagoon from a water body with permanent communication with the sea to the modern seasonally closed system. When sea level rise rates were higher than the rates of sediment infill of the lagoon's basin, the depositional environment was under sea level and pollen assemblages were dominated by regional taxa. The ecological succession towards the establishment of mangrove forest started at $\sim 6,300$ cal BP, but mangrove forests were sparse, resembling those of the modern northern sub-basin because of two main reasons: i) the water column was relatively deep and sedimentary plains for mangrove establishment were likely narrow, and ii) a regional drought lasting from $\sim 5400$ to 3700 BP probably caused extremely high substrate salinity that impeded mangrove forests expansion. Dense mangrove forests alike those that occupy the southern sub-basin today established around $\sim 3500 \mathrm{BP}$, and have dominated the area ever since. associated with the development of the seasonally open mouth. This pairing of lagoon sedimentary accumulation and sea levels defined the latter as the base level for erosion, allowing the accumulation of material during the dry season, and therefore the formation of a damming bar, which would eventually be eventually-open during the rainy season owing to the increased freshwater discharge. Concomitant to this process would be the linear erosion of eanals channels through the sedimentary deposit, conforming the modern geomorphology of the area. The establishment of the mangrove forest implied a substantial increase of sedimentary organic matter, highlighting the role of these ecosystems at storing carbon. Overall, our record demonstrates the complexity of the interactions between local 
and regional factors in the development and evolution of both coastal geomorphology and ecosystems.

\section{Acknowledgements}

This research was funded by Programa de Apoyo a Proyectos de Investigación e

Innovación Tecnológica PAPIIT-UNAM [grant number IN107716], and Consejo Nacional

de Ciencia y Tecnología [grant number 256406]. Alex Correa-Metrio was supported by

Programa de Apoyos para la Superación del Personal Académico de la UNAM (PASPA).

Dayenari Caballero-Rodríguez, Esmeralda Cruz Silva, Roberto Maya Hernández, and

Yosahandy Vázquez Molina are thanked for their assistance in the fieled.

\section{References}

Ball, M.C., 2002. Interactive effects of salinity and irradiance on growth: implications for mangrove forest structure along salinity gradients. Trees, 16, 126-139.

Balsillie, J.H., Donoghue, J.F., 2004. High resolution sea-level history for the Gulf of Mexico since the last glacial maximum. Florida Geological Survey.

Behling, H., Cohen, M.C.L., Lara, R.J., 2001. Studies on Holocene mangrove ecosystems dynamics of the Braganca Peninsula in north-eastern Para, Brazil. Palaeogeography, Palaeoclimatology, Palaeoecology, 167, 225-242.

Blaauw, M., Christen, J.A., 2011. Flexible paleoclimate age-depth models using an autoregressive gamma process. Bayesian Analysis, 6, 457-474.

Bouillon, S. et al., 2008. Mangrove production and carbon sinks: a revision of global budget estimates. Global Biogeochemical Cycles, 22.

Bouillon, S., Dahdouh-Guebas, F., Rao, A., Koedam, N., Dehairs, F., 2003. Sources of organic carbon in mangrove sediments: variability and possible ecological implications. Hydrobiologia, 495, 33-39.

Bush, M.B., 2002. On the interpretation of fossil Poaceae pollen in the lowland humid neotropics. Palaeogeography, Palaeoclimatology, Palaeoecology, 177, 5-17.

Carrillo-Bastos, A., Islebe, G.A., Torrescano-Valle, N., González, N.E., 2010. Holocene vegetation and climate history of central Quintana Roo, Yucatan Peninsula, Mexico. Review of Palaeobotany \& Palynology, 160, 189-196.

Colinvaux, P., de Olivera, P.E., Moreno, P.J.E., 1999. Amazon Pollen Manual and Atlas. Harwood Academic Publishers, Amsterdam.

Formatted: Spanish (Mexico)

Formatted: Spanish (Mexico) 
Correa-Metrio, A., Bush, M.B., Lozano-García, M.S., Sosa-Nájera, S., 2013. Millennial-scale temperature change velocity in the continental northern Neotropics. PLoS ONE, 8, e81958.

Correa-Metrio, A., Bush, M.B., Pérez, L., Schwalb, A., Cabrera, K.R., 2011. Pollen distribution along climatic and biogeographic gradients in northern Central America. The Holocene, 21, 681692.

Davis, R.A., 2011. Sea-level change in the Gulf of Mexico. Texas A\&M University Press, Corpus Christi.

Ellison, J.C., 1989. Pollen analysis of mangrove sediments as a sea-level indicator: assessment from Tongatapu, Tonga. Palaeogeography, Palaeoclimatology, Palaeoecology, 74, 327-341.

Ellison, J.C., 2008. Long-term retrospection on mangrove development using sediment cores and pollen analysis: a review. Aquatic Botany, 89, 93-104.

Faegri, K., Iversen, J., 1989. Textbook of pollen analysis. 4th ed. Wiley, Chichester.

Faith, D.P., Minchin, P.R., Belbin, L., 1987. Compositional dissimilarity as a robust measure of ecological distance. Vegetatio, 69, 57-68.

FAO-UNEP, 2007. The world's mangroves 1980-2005. FAO Forestry Paper.

Feller, I.C., Friess, D.A., Krauss, K.W., Lewis, R.R., 2017. The state of the world's mangroves in the 21st century under climate change. Hydrobiologia, 803, 1-12.

Franco-Gaviria, F. et al., 2018. The human impact imprint on the modern pollen spectra of the Maya lands. Boletín de la Sociedad Geológica Mexicana, 70, 61-78.

Geissert Kientz, D., 1999. Regionalización geomorfológica del estado de Veracruz. Investigaciones geográficas, 23-47.

Gilman, E.L., Ellison, J., Duke, N.C., Field, C., 2008. Threats to mangroves from climate change and adaptation options: a review. Aquatic botany, 89, 237-250.

González, C., Dupont, L.M., 2009. Tropical salt marsh succession as sea-level indicator during Heinrich events. Quaternary Science Reviews, 28, 939-946.

González, C., Urrego, L.E., Martínez, J.I., Polanía, J., Yokoyama, Y., 2010. Mangrove dynamics in the southwestern Caribbean since the 'Little Ice Age': A history of human and natural disturbances. The Holocene, 20, 849-861.

Hamilton, S.E., Casey, D., 2016. Creation of a high spatio-temporal resolution global database of continuous mangrove forest cover for the 21st century (CGMFC-21). Global Ecology and Biogeography, 25, 729-738.

Haug, G.H., Hughen, K.A., Sigman, D.M., Peterson, L.C., Rohl, U., 2001. Southward migration of the Intertropical Convergence Zone through the Holocene. Science, 293, 1304-1308.

Hogarth, P.J., 2015. The biology of mangroves and seagrasses. Oxford University Press, Oxford.

Hooghiemstra, H., Lézine, A.M., Leroy, S.A.G., Dupont, L., Marret, F., 2006. Late Quaternary palynology in marine sediments: A synthesis of the understanding of pollen distribution patterns in the NW African setting. Quaternary International, 148, 29-44.

Kjerfve, B., 1994. Coastal lagoon processes. Elsevier, Amsterdam.

Krauss, K.W. et al., 2008. Environmental drivers in mangrove establishment and early development: a review. Aquatic Botany, 89, 105-127.

Lankford, R.R., 1977. Coastal lagoons of Mexico their origin and classification, Estuarine Processes: Circulation, Sediments, and Transfer of Material in the Estuary. Elsevier, pp. 182-215.

Legendre, P., Legendre, L., 2012. Numerical Ecology. Elsevier Scientific, Oxford.

López-Portillo, J., 2011. Atlas de las costas de Veracruz: manglares y dunas [costeras]. Gobierno del Estado de Veracruz, Secretaría de Educación, Xalapa.

Lugo, A.E., Snedaker, S.C., 1974. The ecology of mangroves. Annual review of ecology and systematics, 5, 39-64.

\section{Formatted: Spanish (Mexico)}

Formatted: Spanish (Mexico)

Formatted: Spanish (Mexico)

Formatted: Spanish (Mexico) 
Marchant, R. et al., 2002. Distribution and ecology of parent taxa of pollen lodged within the Latin American Pollen Database. Review of Palaeobotany and Palynology, 121, 1-75.

Méndez Linares, A., López-Portillo, J., Hernández-Santana, J., Pérez, M.O., Orozco, O.O.J.C., 2007. The mangrove communities in the Arroyo Seco deltaic fan, Jalisco, Mexico, and their relation with the geomorphic and physical-geographic zonation. 70, 127-142.

Metcalfe, S.E., O'Hara, S.L., Caballero, M., Davies, S.J., 2000. Records of Late Pleistocene-Holocene climate change in Mexico- a review. Quaternary Science Reviews, 19, 699-721.

Meyers, P.A., 1997. Organic geochemical proxies of paleoceanographic, paleolimnologic, and paleoclimatic processes. Organic geochemistry, 27, 213-250.

Milliken, K., Anderson, J.B., Rodriguez, A.B., 2008. A new composite Holocene sea-level curve for the northern Gulf of Mexico. Geological Society of America Special Paper, 443, 1-11.

Moreno-Casasola, P., 2006. Entornos veracruzanos: la costa de La Mancha, Instituto de Ecología, A.C., Xalapa, Veracruz, Mexico.

Mueller, A.D. et al., 2010. Late Quaternary palaeoenvironment of northern Guatemala: evidence from deep drill cores and seismic stratigraphy of Lake Petén Itzá. Sedimentology, 57, 12201245.

Parkinson, R.W., DeLaune, R.D., White, J.R., 1994. Holocene sea-level rise and the fate of mangrove forests within the wider Caribbean region. Journal of Coastal Research, 10771086.

Ramírez-Marcial, N., González-Espinosa, M., Williams-Linera, G., 2001. Anthropogenic disturbance and tree diversity in montane rain forests in Chiapas, Mexico. Forest Ecology Management, 154, 311-326.

Ranwell, D.S., 1972. Ecology of salt marshes and sand dunes, Ecology of salt marshes and sand dunes. Chapman and Hall, London, pp. 200 pp.

Reimer, P.J. et al., 2013. IntCal13 and Marine13 radiocarbon age calibration curves $0-50,000$ years cal BP. Radiocarbon, 55, 1869-1887.

Renssen, H. et al., 2009. The spatial and temporal complexity of the Holocene thermal maximum. Nature Geoscience, 2, 411-414.

Richardson, D.M., 1998. Ecology and Biogeography of Pinus. Cambridge University Press, Cambridge.

Rzedowski, J., 2006. Vegetación de México. Comisión Nacional para el Conocimiento y Uso de la Biodiversidad, México D.F., pp. 504 pp.

Servicio Meteorologico Nacional, 2018. Normales climatológicas, Estado de Veracruz, Estación La Mancha (online,last accessed June 2018).

Soares, M., 2009. A conceptual model for the responses of mangrove forests to sea level rise. Journal of Coastal Research, 267-271.

Suárez, J.A., Urrego, L.E., Osorio, A., Ruiz, H.Y., 2015. Oceanic and climatic drivers of mangrove changes in the Gulf of Urabá, Colombian Caribbean. Latin American Journal of Aquatic Research, 43.

Thom, B.G., 1967. Mangrove ecology and deltaic geomorphology: Tabasco, Mexico. The Journal of Ecology, 301-343.

Thorhaug, A., Poulos, H.M., López-Portillo, J., Ku, T.C., Berlyn, G., 2017. Seagrass blue carbon dynamics in the Gulf of Mexico: Stocks, losses from anthropogenic disturbance, and gains through seagrass restoration. Science of The Total Environment, 605, 626-636.

Toscano, M.A., Macintyre, I.G., 2003. Corrected western Atlantic sea-level curve for the last 11,000 years based on calibrated $14 \mathrm{C}$ dates from Acropora palmata framework and intertidal mangrove peat. Coral reefs, 22, 257-270.
Formatted: Spanish (Mexico)

Formatted: English (United States)

Formatted: Spanish (Mexico)

Formatted: English (United States)

Formatted: Spanish (Mexico) 
Travieso-Bello, A., 2000. Biodiversidad del paisaje costero de La Mancha, Actopan, Veracruz. Instituto de Ecología, Xalapa.

Urrego, L.E., Bernal, G., Polanía, J., 2009. Comparison of pollen distribution patterns in surface sediments of a Colombian Caribbean mangrove with geomorphology and vegetation. Review of Palaeobotany and Palynology, 156, 358-375.

Urrego, L.E., Correa-Metrio, A., González, C., Castaño, A.R., Yokoyama, Y., 2013. Contrasting responses of two Caribbean mangroves to sea-level rise in the Guajira Peninsula (Colombian Caribbean). Palaeogeography, Palaeoclimatology, Palaeoecology, 370, 92-102.

Urrego, L.E., Correa-Metrio, A., González-Arango, C., 2018. Colombian Caribbean mangrove dynamics: anthropogenic and environmental drivers. Boletín de la Sociedad Geológica Mexicana, 70, 133-145.

Urrego, L.E., González, C., Urán, G., Polanía, J., 2010. Modern pollen rain in mangroves from San Andres Island, Colombian Caribbean. Review of Palaeobotany and Palynology, 162, 168182.

Valiela, I., Bowen, J.L., York, J.K., 2001. Mangrove Forests: One of the World's Threatened Major Tropical Environments. Bioscience, 51, 807-815.

Vovides, A.G. et al., 2014. Morphological plasticity in mangrove trees: salinity-related changes in the allometry of Avicennia germinans. Trees, 28, 1413-1425.

Ward, R.D., Friess, D.A., Day, R.H., MacKenzie, R.A., 2016. Impacts of climate change on mangrove ecosystems: a region by region overview. Ecosystem Health Sustainability, 2, e01211.

Williams-Linera, G., 2002. Tree species richness complementarity, disturbance and fragmentation in a Mexican tropical montane cloud forest. Biodiversity \& Conservation, 11, 1825-1843.

Wooller, M.J., Morgan, R., Fowell, S., Behling, H., Fogel, M., 2007. A multiproxy peat record of Holocene mangrove palaeoecology from Twin Cays, Belize. The Holocene, 17, 1129-1139.

Zar, J.H., 1999. Biostatistical Analysis. 4th ed. Prentice-Hall, Upper Saddle River, NJ. 
Cordero-Oviedo, C ${ }^{\mathrm{a}}$, A. Correa-Metrio ${ }^{\mathrm{b}, *}$, L.E. Urrego ${ }^{\mathrm{c}}$, G. Vázquez-Hurtado ${ }^{\mathrm{d}}, \mathrm{M}$.

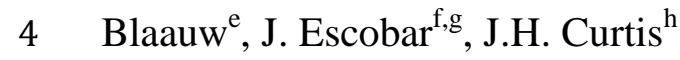

${ }^{a}$ Posgrado en Ciencias de la Tierra, Universidad Nacional Autónoma de México, Coyoacán, Ciudad de México, México 04510, ceciliacorderoviedo@gmail.com, ${ }^{\text {b }}$ Instituto de Geología, Universidad Nacional Autónoma de México, Coyoacán, Ciudad de México, México 04510, acorrea@geologia.unam.mx, ${ }^{\mathrm{c}}$ Departamento de Ciencias Forestales, Universidad Nacional de Colombia, Sede Medellín A.A. 568 Medellín, Colombia, leurrego@unal.edu.co, ${ }^{\mathrm{d}}$ Instituto de Ecología, A.C. Carretera antigua a Coatepec 351, El Haya, Xalapa 91070, Veracruz, México, gabriela.vazquez@inecol.mx, ${ }^{\text {e }}$ School of Natural and Built Environment, Queen's University Belfast, Belfast, United Kingdom, maarten.blaauw@qub.ac.edu, ${ }^{\mathrm{f}}$ Departamento de Ingenieria Civil y Ambiental, Universidad del Norte, Km 5 Via Puerto Colombia, Colombia, jhescobar@uninorte.edu.co, ${ }^{\mathrm{g}}$ Center for Tropical Paleoecology and Archaeology, Smithsonian Tropical Research Institute, Box 0843-03092, Balboa, Panama, ${ }^{\text {h }}$ Department of Geological Sciences, University of Florida, Gainesville, FL, 32611, USA, curtisj@ufl.edu

*Corresponding autor: Alexander Correa-Metrio, acorrea@geologia.unam.mx

\section{Abstract}

The successful establishment of mangrove ecosystems depends on an intricate network of interactions among physical and biological factors that are highly dynamic through time. At millennial to centennial time scales, regional climates, sea levels, and local geomorphology 
26 play critical roles in the establishment of mangroves. Whereas fluvio-marine dynamics

27 define coastal sedimentary settings, regional precipitation and freshwater input modulate

28 salinity and seasonal flooding patterns. We analyzed a $\sim 7800$-year-old, continuous

29 sedimentary record from the western coast of the Gulf of Mexico to shed light on regional

30 biophysical coastal processes and the history of the mangroves that occupy the region

31 today. We used a systematic sampling of mud-water interface sediments to generate a

32 modern reference frame for interpreting fossil pollen assemblages. Our results indicate that

33 the cored location that is currently approximately at sea level, was below sea level from

$34 \sim 7800$ to 4000 calibrated years before present (cal BP). The establishment of dense

35 mangrove stands took place around $3700 \mathrm{cal} \mathrm{BP}$, when regional sea levels stabilized,

36 resulting in a substantial increase of organic matter and therefore carbon stored in the

37 sediments. However, the mangrove ecological succession that started at $\sim 6000$ cal BP was

38 interrupted by a regional drought that extended from $\sim 5400$ to $3700 \mathrm{cal} \mathrm{BP}$. From $3700 \mathrm{cal}$

39 BP to Present, the lagoon has been characterized by relatively stable both substratum and

40 sea level, that together have facilitated the establishment of mangrove forests. Overall, our

41 record demonstrates the complexity of the interactions between local and regional factors in

42 the development and evolution of both coastal geomorphology and ecosystems.

44 Keywords: coastal environment; Gulf of Mexico; Holocene; mangroves; sea-level changes;

45 pollen analysis

\section{1. Introduction}


48 Mangrove ecosystems are a large component of tropical and sub-tropical coastal

49 landscapes. Occupying intertidal zones (Lugo and Snedaker, 1974), they regulate the

50 relationship between continental discharge of sediments and water and sea level (Ellison,

51 1989). The main engineers of these ecosystems are a reduced group of plant species

52 physiologically adapted to brackish-to-saline substrates (Ball, 2002; Vovides et al., 2014).

53 The establishment of mangrove forests creates the conditions for complex food webs that

54 incorporate marine and continental components. The entire mangrove ecosystem is

55 fundamental for providing products and ecological services, resulting in direct and indirect

56 uses by human populations, mainly fuelwood, fisheries, sediment trapping, and carbon

57 storage (Bouillon et al., 2008; Feller et al., 2017; Méndez et al., 2007; Ward et al., 2016).

58 Although they represent one of the most important carbon sinks worldwide

59 (Bouillon et al., 2008), together with coral reefs and tropical forests, mangroves are among

60 the most endangered modern ecosystems (Valiela et al., 2001). It has been estimated that

61 through the last two decades of the 20th Century, 35\% of the global mangrove area had

62 been lost mostly because of direct and/or indirect anthropogenic causes (FAO, 2007). The

63 main human-related causes of mangroves loss are the conversion to aquaculture and

64 agriculture, urbanization, and pollution (Feller et al., 2017; Gilman et al., 2008; Thorhauga

65 et al., 2017), which in Mexico have translated in a net loss 240 ha/year through the last

66 decades (Hamilton and Cassey, 2016). The rapid rate at which these threats to mangrove

67 ecosystems are growing highlights the need to understand them in the context of their

68 natural history and the intricate network of factors that interact to facilitate or impede their

69 colonization and establishment. 
A wide variety of factors interact to create the specific conditions under which

71 mangrove communities thrive and persist through time (Gilman et al., 2008). Healthy

72 vigorous mangrove forests, and therefore ecosystems, depend on a delicate balance

73 between marine influences and freshwater and sediment input from continental areas acting

74 upon specific geomorphologic settings (Lugo and Snedaker, 1974; Soares, 2009). Whereas

75 marine influences on mangrove ecosystems materialize through tidal regimes and sea level

76 changes that define baseline for erosion and accumulation of sediments, regional climates

77 and vegetation cover over the mainland control continental discharge of freshwater and

78 sediments along the coast. Thus, through the Holocene, changes in precipitation, vegetation

79 cover, geomorphologic dynamics, and sea levels have probably led to high environmental

80 variability over the intertidal areas (Geissert Kientz, 1999). In the Gulf of Mexico and the

81 Caribbean, regional sea levels have progressively risen since the deglaciation (Milliken and

82 Anderson, 2008; Toscano and Macintyre, 2003), whereas annual precipitation has shown a

83 wide variability associated with extraterrestrial forcings (e.g. solar activity and orbital

84 cycles, Haug et al. 2001, Hodell et al. 2001) and higher frequency processes associated with

85 complex internal systems (e.g. El Niño-Southern Oscillation, Moy et al. 2002). The balance

86 between fluvial loads and sea-level rise modulates local geomorphologic and sedimentary

87 processes, defining the formation of either depositional or erosional environments the

88 balance of which is in turn critical for the establishment and persistence of mangroves

89 (Parkinson et al., 1994). Indeed, modern net losses of mangrove cover have been widely

90 associated with sea-level rises along unprotected coasts (Suárez et al., 2015). Thus, the

91 definition of the context that led to the development of modern mangrove forests would

92 provide important clues for identifying the limits of environmental pressure that these

93 ecosystems can endure. 
Sedimentary deposits that accumulate in coastal lagoons provide a natural record of

95 the evolution of coastal landscapes through time. Understanding the natural development of

96 mangrove ecosystems and the main factors involved in the process would give insights into

97 the threat level that coastal zones face given modern environmental change (Lopez-Portillo

98 et al., 2011; Thom, 1967). Here we use the pollen record of a 13-m-long 8,000-year-old

99 sedimentary sequence retrieved from La Mancha Lagoon, State of Veracruz, Mexico, to

100 reconstruct the history of the local vegetation through the Holocene. By analyzing the

101 history of vegetation assemblages as reflected by fossil pollen spectra, we aim to answer

102 the following questions: i) what has been the role of sea-level rise and precipitation

103 variability through the Holocene in the establishment and persistence of mangrove forests

104 in the west coastline of the Gulf of Mexico? ii) when did the barrier-lagoon systems of the

105 region consolidate in the context of Holocene environmental variability?

\section{Study Area}

La Mancha lagoon is located in the State of Veracruz, Mexico, on the western

109 coasts of the Gulf of Mexico (19.579 N, $96.387 \mathrm{~W}^{\circ}$, Fig. 1). With a north-to-south length

110 of $3 \mathrm{~km}$, the lagoon has an area of $\sim 1.35 \mathrm{~km}^{2}$ distributed in two sub-basins separated by a

111 strait located near the center of the water body (Fig. 1). Whereas the southern sub-basin is

112 exposed to permanent freshwater input from the Caño Grande River that drains water from

113 a basin of almost $2,500 \mathrm{~km}^{2}$, the northern sub-basin more exposed to tidal influence

114 through an ephemeral mouth that communicates seasonally with the sea (Fig.1) (Lankford,

115 1977; Moreno-Casasola, 2006). During the dry season, a sand bar accumulates closing the

116 estuarine mouth and causing a damming of continental freshwater. With the onset of the 
117 rainy season, freshwater starts to accumulate, eventually breaking the sandbar, opening the 118 mouth, and creating a direct connection with the sea (Moreno-Casasola, 2006). Thus, 119 lagoon dynamics are intimately linked to regional climate that is warm (temperatures from 12022 to $26^{\circ} \mathrm{C}$ ), with an annual mean precipitation of $1222 \mathrm{~mm}$, with $85 \%$ of the annual value 121 falling between June and October (Fig. 1) (Servicio Meteorologico Nacional, 2018). The 122 dry season is especially pronounced between December and April with mean monthly 123 precipitation below $20 \mathrm{~mm}$, while November and May are characterized by a mean 124 precipitation around $50 \mathrm{~mm}$. By the end of the summer and early autumn, the area is 125 exposed to tropical cyclones, although their incidence is relatively low compared with other 126 areas of the Gulf of Mexico (Moreno-Casasola, 2006).

127 La Mancha lagoon belongs to a geomorphic unit known as the Low Cumulative 128 Plain that formed during the Quaternary (Geissert Kientz, 1999), allowing deposition of 129 clayey-silt sediments. The lagoon formed at the margin of a volcanic mountain range that 130 interrupts the coastal plain of the Gulf of Mexico (Geissert Kientz, 1999; Fig. 1). The 131 current morphology of the area has been mostly shaped by Quaternary dynamics, going 132 from an empty deep basin during times of sea-level low stands to a depositional coastal 133 plain during times of sea-level high stands (Geissert Kientz, 1999; Kjerfve, 1994). The 134 mountain ridge that connects La Mancha Hill with the adjacent western mountains divides 135 La Mancha lagoon into two contrasting sub-basins (Fig. 1). Differences in freshwater input, 136 marine influence, and energy of the sedimentary environments have created two clearly 137 distinct environments for mangrove forests, which today occupy $\sim 3.55 \mathrm{~km}^{2}$ around the 138 lagoon.

139 Regional tides are mixed, mostly diurnal and of low amplitude (highest and lowest 140 tidal levels at $22 \mathrm{~cm}$ and $-30 \mathrm{~cm}$ from average sea level, respectively), preventing the 
141 formation of tidal currents. This feature together with the permanent input of fresh water 142 and the sheltering of the lagoon from the energy of the waves by La Mancha Hill (Fig. 1)

143 have probably played a critical role in maintaining the morphology of the lagoon, avoiding 144 the formation of tidal mudflats, marshes, and/or estuaries (Geissert Kientz, 1999). Over 145 recent decades, progressive loss of depth of the lagoon because of sediment accumulation 146 suggests that sediment input surpasses local erosion (Moreno-Casasola, 2006), although 147 this might not have been the case through the entire history of the area.
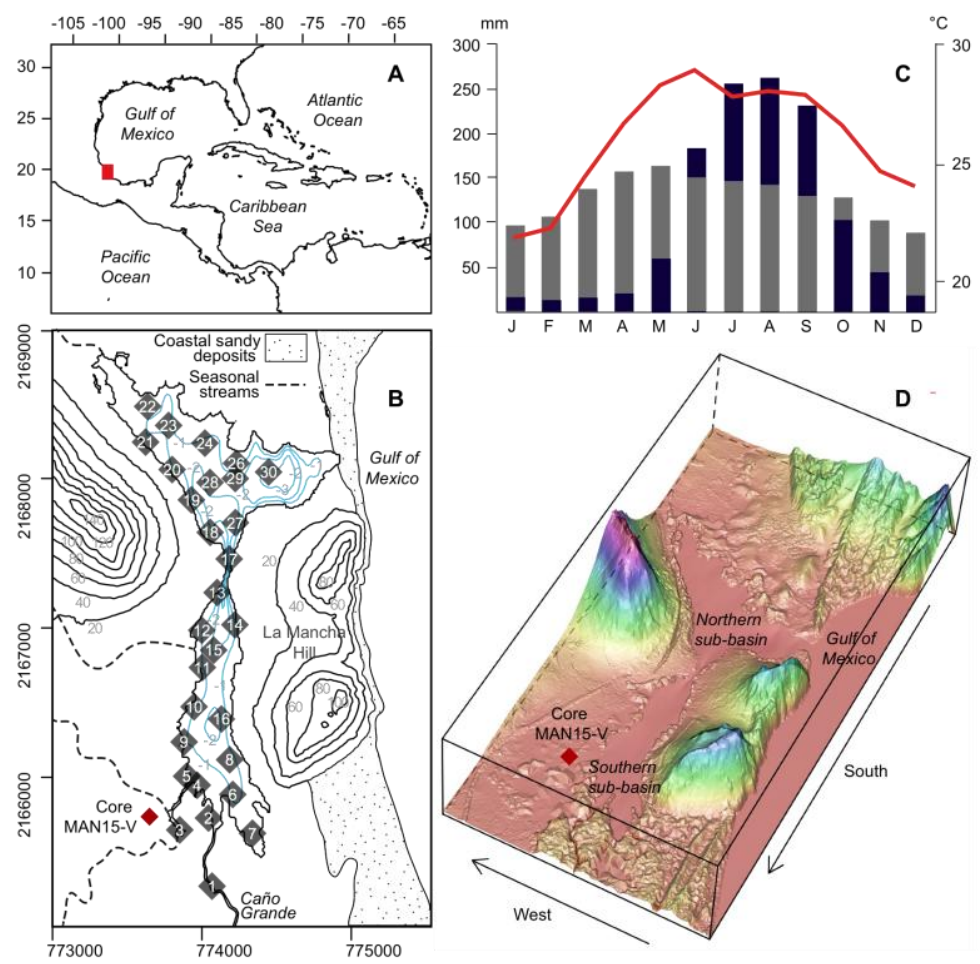

149 Figure 1. Study area. A. Location of La Mancha lagoon in the continental context. B.

150 Locations sampled for modern and fossil sediments in the local context of La Mancha

151 coastal lagoon; elevation contours are shown in increments of $20 \mathrm{~m}$ asl (solid black lines),

152 whereas a basic bathymetry based on field observations is shown as blue contours. C.

153 Monthly precipitation (blue bars), evapotranspiration (gray bars), and monthly mean 
temperature (black line with dots) at La Mancha Meteorological Station (Servicio

155 Meteorologico Nacional, 2018) D. Topographic representation of La Mancha coastal 156 lagoon.

Pollen assemblages contained in sediments reflect parental vegetation and are therefore useful for reconstructing environmental dynamics through time (e.g. Carrillo-

160 Bastos et al., 2010; Urrego et al., 2009; Urrego et al., 2018). Given the regional

161 geomorphology, the large size of the catchment basin of Caño Grande River, and the

162 proximity to high mountain ranges, the pollen spectra of sediments from La Mancha lagoon

163 contains regional and local taxa (Moreno-Casasola, 2006; Travieso-Bello, 2000). Whereas

164 the former are transported by water and wind currents, the latter are produced by in situ 165 vegetation (Hooghiemstra et al., 2006). Regional elements come mostly from montane 166 forests that dominate the regional highlands (Rzedowski, 2006; Williams-Linera, 2002) and 167 are characterized by wind-pollinated taxa with long-distance pollen dispersal (e.g. Alnus, 168 Myrica, Ulmaceae, Quercus, and Pinus), which tend to be overrepresented in the pollen 169 spectra. From within these allochthonous elements, Pinus is worth noticing because of the 170 opportunist nature of most of the parental species (Richardson, 1998), which results in a 171 high representation of this taxon in pollen spectra when environmental conditions are 172 suboptimal for other arboreal elements (e.g. during drughts, Correa-Metrio et al., 2013).

173 Local elements of the pollen spectra are in turn associated with two main vegetation types, 174 namely lowland and mangrove forests. The hills that surround the lagoon reach heights up 175 to $300 \mathrm{~m}$ asl and are mostly occupied by species of Desmodium, Inga, Machaerium, 176 Psychotria, Protium, Bursera, Moraceae-Urticaceae and Acacia. The salt marshes, coastal 177 dunes, and beaches that characterize flood plains are mainly dominated by species of 
178 Cyperaceae, Amaranthaceae, Typha, Asteraceae, Chenopodiaceae, Mimosa and Croton.

179 These vegetation types can be associated with the distal part of a marine transgression

180 plain, or be related to the first stage of a progradational pattern indicative of a typical

181 ecological succession on intertidal habitats (González and Dupont, 2009).

182 The edges of the lagoon are occupied by species typical of mangrove forests,

183 Rhizophora mangle, Avicennia germinans, Conocarpus erectus and Laguncularia

184 racemosa (Travieso-Bello, 2000). The interplay of these species is modulated by their

185 differential adaptation to the changing environmental conditions along a salinity gradient,

186 which in turn defines the structure and composition of the forest (Lugo and Snedaker, 1974;

187 Travieso-Bello, 2000; Urrego et al., 2009). Thus, these forests are highly sensitive to

188 changes in sea-level, coastal progradation and/or erosion at different time scales (Ellison,

189 2008). Mangrove forest species are adapted to specific environmental conditions, with $R$.

190 mangle tolerating high inundation levels, strong wave energy and shorter distances to the

191 sea, A. germinans thriving in more saline environments, hurricane-disturbed or

192 experiencing severe droughts, $L$. racemosa being restricted to average minimum

193 temperatures over $15.5^{\circ} \mathrm{C}$ and successional processes triggered by anthropogenic

194 disturbance, and C. erectus being tolerant to higher sediment $\mathrm{pH}$ typical of supra-tidal

195 waters close to well drained forests (González et al., 2010; Hogarth, 2007; Urrego et al.,

196 2009; Urrego et al., 2010).

197 Regional human occupation has been reported since at least $\sim 4,600 \mathrm{BP}$, and the

198 lagoon has apparently been an important source of resources for human populations

199 (Moreno-Casasola, 2006). This factor has exerted direct pressure on the mangrove forest

200 through deforestation for timber and fuel wood extraction, and more recently in the

201 interruption of surface and subsurface flows in the by infrastructure of the oil industry. 
These local factors have been especially harsh on the northern sub-basin, where only sparse

203 remnants of the mangrove forest survive today. Thus, whereas vigorous mangrove forests

204 surround the southern sub-basin, the northern sub-basin is occupied by highly disturbed

205 vegetation including sparse mangrove remnants. Regionally, growing human population

206 and the parallel development of infrastructure apply further pressures to coastal ecosystems

207 through pollution, accelerated erosion, increasing sea level, among other elements (Gilman

208 et al., 2008).

209

\section{3. Methods}

2113.1 Field work and laboratory analysis

212 In autumn 2015, a 13-meter-long core was recovered from the southern part of La Mancha

213 coastal lagoon (core MAN15V, Fig. 1), under an A. germinans stand, using a modified

214 Livingston piston corer (Colinvaux et al., 1999). The core was longitudinally sectioned,

215 stratigraphically described, and stored at $\sim 4^{\circ} \mathrm{C}$ to preserve the sedimentary evidence. The

216 chronological control of the sedimentary sequence was based on eight accelerator-mass-

217 spectrometer (AMS) radiocarbon dates of bulk sediment, given that no other material such

218 as macrofossils or charcoal could be found. Radiocarbon dates were calibrated to years

219 before present (hereafter cal BP) using the IntCal13 curve (Reimer et al., 2013), and

220 calibrated dates were used to build a Bayesian age-depth model using Bacon (Blaauw and

221 Christen, 2011). The core was subsampled every $\sim 12.5 \mathrm{~cm}$ for pollen analysis, aiming at a

222 temporal resolution of $\sim 75$ years between contiguous samples. A total of 104 samples were

223 processed for pollen analysis using standard pollen extraction techniques (Faegri and

224 Iversen, 1989). Samples were analyzed under transmitted-light microscope at 
225 magnifications of $\times 400$ and $\times 1000$, aiming to reach a minimum pollen sum of 300 pollen

226 grains. Grains of the family Cyperaceae and pteridophytes spores were excluded from the

227 pollen sum, although they were counted and included in the interpretation. Pollen counts

228 were transformed into percentages of the pollen sum and a stratigraphic pollen diagram was

229 constructed.

230 Pollen taxa were classified into five groups according to their modern ecological

231 affinities (ecological affinities after Lugo and Snedaker 1974, Ranwell 1972, Travieso-

232 Bello 2000): i) mangroves represented by Rhizophora mangle, Avicennia germinans, and

233 Conocarpus erectus; although Laguncularia racemosa is an important component of the

234 local mangrove forests, it was not found in the pollen spectra; ii) salt marsh vegetation

235 represented by Cyperaceae, Amaranthaceae, Croton, Typha, Asteraceae, Chenopodiaceae,

236 and Mimosa; iii) lowland forest represented by Inga, Acacia, Machaerium, Protium,

237 Bursera, and Moraceae-Urticaceae; iv) montane regional forests represented by Alnus,

238 Myrica, Ulmaceae, Quercus, and Miconia; and v) disturbance taxa represented by Pinus

239 and Poaceae; these latter taxa were classified as representatives of disturbance because in

240 Mexico they are distributed along environments unfavorable to vegetation development,

241 usually associated with either natural or anthropogenic causes (Franco-Gaviria et al., 2018;

242 Rzedowski, 2006). High abundances of Pinus pollen have been reported for areas subjected

243 to dry conditions and/or regimes of high disturbance (Correa-Metrio et al., 2013; Metcalfe

244 et al., 2000), mostly associated with early succession colonizers (Ramirez-Marcial et al.,

245 2001). Meanwhile, although Poaceae pollen is characteristic of successional processes of

246 supratidal plains (Bush, 2002; Urrego et al., 2013), it is also found in pollen assemblages 
247 from all Mexican vegetation types, usually associated with disturbance (Correa-Metrio et 248 al., 2013; Franco-Gaviria et al., 2018).

The fossil pollen record was complemented by sampling 30 locations

250 homogeneously for modern mud-water interface (15 samples from each sub-basin)

251 distributed across the water body, using an Ekman dredge. This sampling was meant to

252 cover the variability of the modern pollen spectra (Fig.1), especially the differences

253 between depositional environments of the two sub-basins. Samples were treated and

254 analyzed using the same techniques as the fossil samples.

255 Total both $\mathrm{C}(\% \mathrm{TC})$ and $\mathrm{N}(\% \mathrm{TN})$ were measured in fossil samples every $5 \mathrm{~cm}$

256 along the core and in modern samples. For this purpose, samples were freeze dried and

257 crushed, and subsequently analyzed using a Carlo Erba NA1500 CNS elemental analyzer.

258 Additionally, coulometric titration was used to determine carbonate carbon (\% TIC) in

259 modern samples, allowing the estimation of organic carbon (\%TOC). The discrimination of

260 TC into TIC and TOC in modern samples was used to infer the relationship between these

261 two carbon sources in the system of La Mancha lagoon.

263 3.2 Statistical Analysis

264 A non-metric multidimensional scaling ordination (NMDS) was applied on pollen relative

265 abundances, including both modern and fossil samples. The ordination was performed to

266 summarize the temporal variability of the pollen spectra, and to evaluate vegetation

267 temporal dynamics in the context of the modern lagoon. This technique ordinates samples

268 on a $k$-dimensional space defined $a$ priori by the analyst, aiming to maintain the original 
269 topologic relationships among samples (Legendre and Legendre, 2012). Although two-

270 dimensional ordinations are readily used, we selected three dimensions to produce a relaxed

271 ordination where the affinity among pollen spectra can manifest more freely. We used the

272 Bray-Curtis metric to estimate dissimilarity among samples, a metric that relies more on

273 compositional data than on the abundance of individual taxa and has been proven

274 monotonic to ecological distance (Faith et al., 1987).

275 Modern samples were classified into southern and northern sub-basins as

276 representative of dense and sparse mangrove forests, respectively. Whereas the northern

277 sub-basin has direct contact with the sea through the ephemeral mouth, which creates a

278 more energetic environment, and has been subjected to important human disturbances and

279 modifications resulting in sparse mangrove cover, the southern sub-basin is more

280 influenced by the entrance of the river and is occupied by a well-developed dense

281 mangrove stand. Thus, pollen spectra from these two sub-basins should reflect contrasting

282 mangrove-forest cover conditions, and their relative oceanic and fluvial influences. The

283 statistical significance of the difference between NMDS sample scores of the two sub-

284 basins were tested using a two-sample t-test (Zar, 1999). TIC, TOC, TC, and TN content in

285 modern samples were compared using Pearson correlation coefficient, whereas

286 comparisons of concentrations between the northern and southern sub-basins were also

287 compared using two-sample t-test (Zar, 1999).

288

289 4. Results

290

4.1 Stratigraphy and chronology of the sedimentary record 
291 Sediments from the La Mancha coastal lagoon were mostly brownish, shelly clays with low 292 content of organic material, and some intermissions of brownish silt with shell fragments 293 and organic material (Fig. 2A). From the base of the core up to $1200 \mathrm{~cm}$ below lagoon floor 294 (blf hereafter), the sediments were brown shelly clay, while from 1200 to $663 \mathrm{~cm}$ blf the 295 color turned into a light brown matrix (clay and silt) with shell fragments and carbonates. 296 From 663 to $615 \mathrm{~cm}$ blf the clayey sediment was brown with light brown bands. From 615 297 to $372 \mathrm{~cm}$ blf, the sediment showed brownish tones, and were mostly composed of clay 298 with a thin layer of silt, shelly and little organic material. The uppermost $327 \mathrm{~cm}$ were dark 299 to very light brown, with a uniform shelly clay composition (Fig 2A).

All radiocarbon dates resulted in stratigraphic order (Table 1). Although bulk

301 sediment dates could lead to an ${ }^{14} \mathrm{C}$ age offset, we were not able to quantify ot because of

302 the lack of other quantifiable materials. Nevertheless, the high correspondence between TC 303 and TN along the sedimentary record (Fig. 2) suggests that inorganic carbon represents a 304 relatively low proportion of the sedimentary material. According to the age-depth model, 305 the core has a basal age of $\sim 7840$ cal BP, resulting in an average sedimentation rate of 1.96 $306 \mathrm{~mm} / \mathrm{yr}$ (Fig 2B). From the bottom of the sequence up to $5500 \mathrm{cal} \mathrm{BP}$, sedimentation rates 307 were high, with maximum values around $5500 \mathrm{cal} \mathrm{BP}(4.10 \mathrm{~mm} / \mathrm{yr})$. From c. $5500 \mathrm{cal}$ BP 308 to present, sedimentation rates showed a decreasing trend, reaching $0.89 \mathrm{~mm} / \mathrm{yr}$ in the 309 uppermost part of the core (Fig 2).

311 Table 1. Radiocarbon dates of core MAN15V from La Mancha coastal lagoon. Depths in 312 cm below lagoon floor (blf). Ages calibrated after the IntCal13 curve (Reimer et al., 2013). 


\begin{tabular}{lcccc}
\hline Laboratory code & Depth (cm blf) & ${ }^{14}$ C Age & Error & $\begin{array}{c}\text { Calibrated age } \\
\text { (95\% range; cal BP) }\end{array}$ \\
\hline UBA-34340 & 109 & 1290 & 24 & $1181-1283$ \\
Beta-440367 & 175 & 1880 & 30 & $1730-1883$ \\
UBA-34341 & 282 & 3447 & 26 & $3637-3826$ \\
Beta-440368 & 373 & 3970 & 30 & $4300-4523$ \\
UBA-34342 & 564 & 4732 & 41 & $5326-5584$ \\
Beta-437078 & 649 & 4770 & 30 & $5334-5588$ \\
UBA-34343 & 979 & 5624 & 41 & $6312-6482$ \\
Beta-437079 & 1249 & 6700 & 30 & $7508-7616$ \\
\hline
\end{tabular}

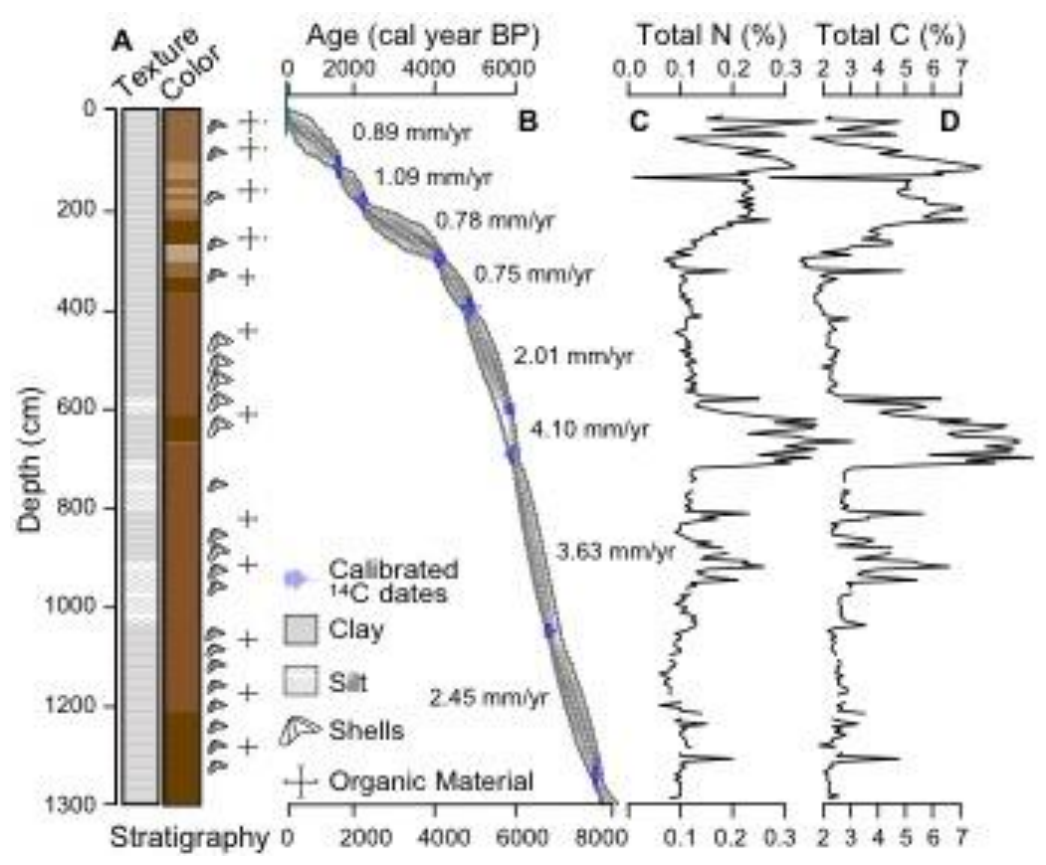

315 Figure 2. Core MAN15V from La Mancha coastal lagoon. A. Stratigraphy of the

316 sedimentary sequence: texture (left), color (right), and organic and shell content. B. Age-

317 depth model; calibrated ages (blue silhouettes), 95\% confidence intervals in grey (darker

318 colors indicate higher probability), and sedimentation rates ( $\mathrm{mm} / \mathrm{yr}) . \mathrm{C}$ and $\mathrm{D}$. Percentage

319 of total nitrogen and total carbon content (TN and TC, respectively). 
322 Modern samples were characterized by 49 taxa, 18 and 31 identified at family and genus

323 levels, respectively. Pollen sums varied between 300 and 387, whereas pollen counts

324 including Cyperaceae and pterodophytes were between 322 and 472 palynomorphs.

325 Rhizophora, Cyperaceae, Moraceae-Urticaceae, Quercus, Pinus, and Poaceae dominated 326 these samples (up to 45\%), whereas taxa such as Typha, Mimosa, Desmodium, Inga, and 327 Ulmaceae were poorly represented (less than 5\%). One sample from the northern sub-basin 328 was barren of pollen (sample 26, Fig. 1).

330 towards the southern sub-basin of the lagoon (Figs. 1 and 3). Contrastingly, other taxa such 331 as Quercus, Myrica, and Pinus decreased southwards. Compositional differences between 332 the northern and southern sub-basins of the lagoon were also indicated by taxa that 333 occurred only at the latter, such as Desmodium, Inga, and Protium (Figs. 1 and 3). Samples 334 from the middle area of the lagoon (samples 12,13,14,17 and 18) (Figs. 1 and 3) contained 335 the highest percentages of Cyperaceae and Moraceae-Urticaceae (25\% and 30\%, 336 respectively), and minima of Typha, Asteraceae, and Psychotria. In the northern sub-basin 337 (Figs. 1 and 3), Quercus, Pinus, and Poaceae dominated the pollen spectra with abundances 338 above $10 \%$. 


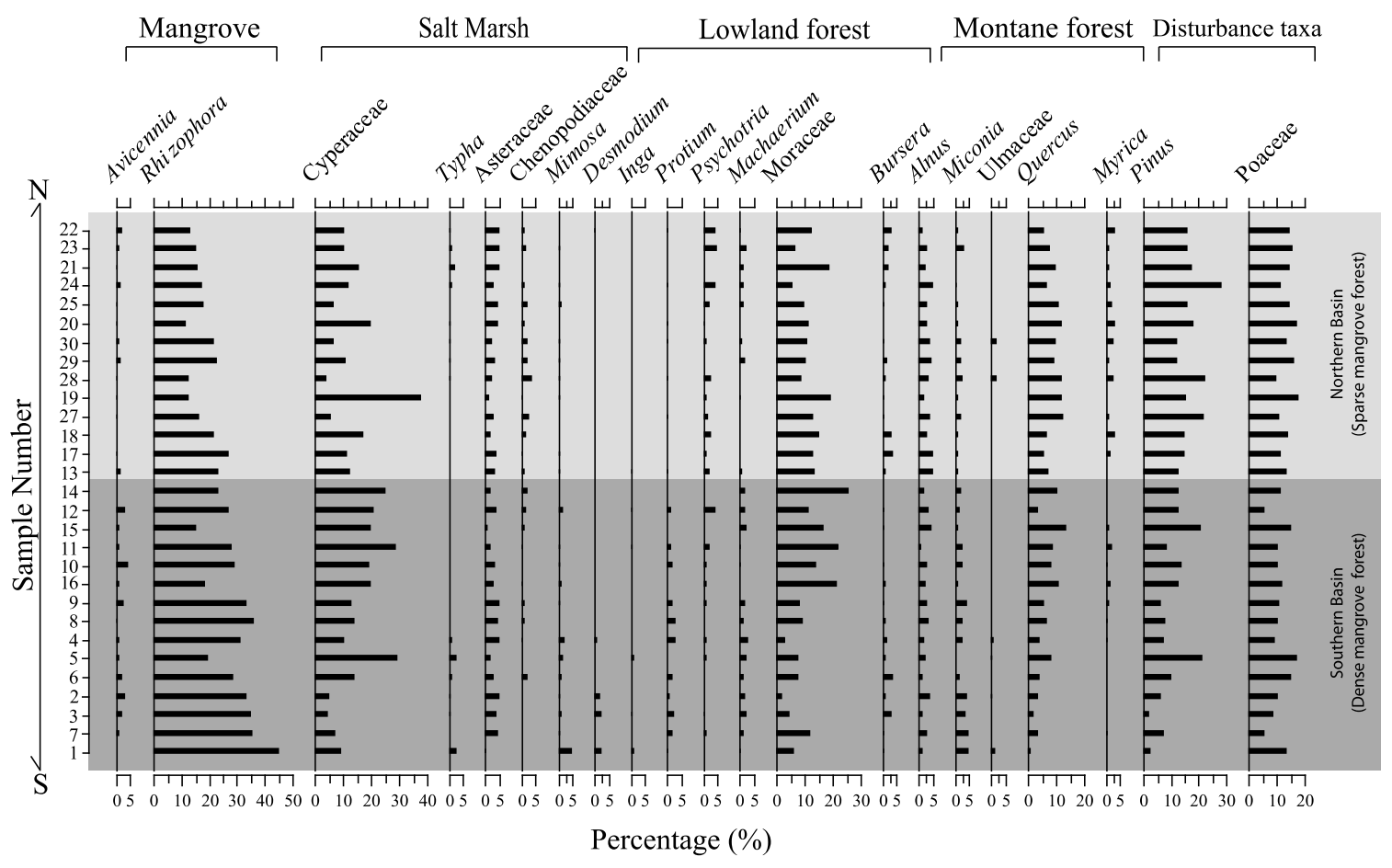

341 Figure 3. Pollen diagram of selected taxa from mud-water interface samples from La

342 Mancha coastal lagoon. Ecological affinities after Lugo and Snedaker (1974), Ramwell

343 (1972), and Travieso-Bello (2000). Samples are ordered from South to North with samples

344 from the southern (northern) sub-basin highlighted in dark (light) grey.

346 TC content in modern samples varied between 3.1 and $12.3 \%$, with mean and median of 4.9

347 and $4.4 \%$, respectively. Although mean values for the northern and southern sub-basins

348 were not statistically differentiable $(\mathrm{t}=1.66$, $\mathrm{p}$-value $=0.11)$, the northern sub-basin

349 consistently showed lower values (Fig. 3). Differently, individual fractions of C resulted

350 statistically differentiable, with a higher concentration of TOC in the southern sub-basin

351 (3.56, $\mathrm{p}$-value $=0.002)$ and a higher concentration of TIC in the northern sub-basin $(\mathrm{t}=-$

3522.47 , $\mathrm{p}$-value $=0.023$ ). TN range between 0.02 and $0.37 \%$ with mean and median of 0.23 
and $0.24 \%$, respectively (Fig. 3), with higher mean concentration in the southern subbasin

$354(\mathrm{t}=5.54, \mathrm{p}$-value $<0.001)$. TC resulted statistically associated with TN, TIC, and TOC,

355 although the magnitude of the correlation was substantially higher with the latter (Fig. 3).

356 Whereas TIC resulted moderately associated only with TN, TOC was strongly associated 357 with both TC and TN (Fig. 3).

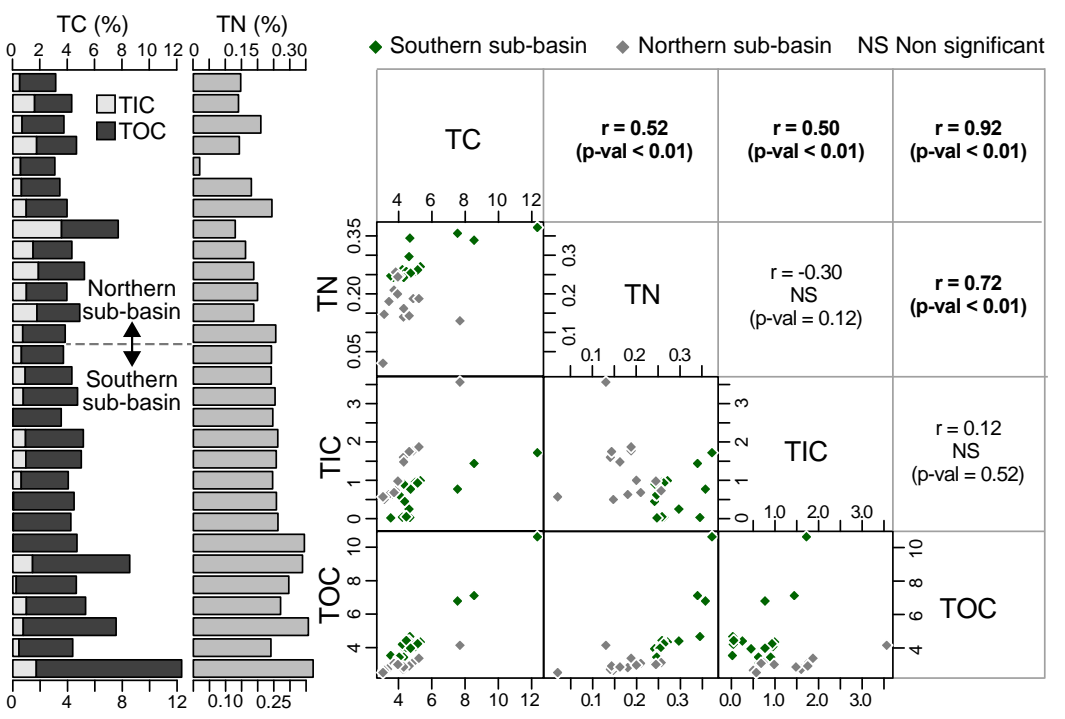

359 Figure 4. Content (\%) of carbon and nitrogen in the modern samples of La Mancha coastal

360 lagoon. Total C content (TC) discriminated into inorganic and organic fractions (TIC and

361 TOC), and total $\mathrm{N}$ content (TN). Comparisons among sedimentary attributes are shown in

362 the right side panels (biplots and correlation coefficients with their significance).

\subsection{Fossil record}

365 Fossil pollen types included 55 taxa classified into 24 families and 31 genera. Pollen sums

366 varied between 300 and 349 grains per sample (average 306 grains), whereas pollen counts

367 that included Cyperaceae and pterodophytes reached between 303 and 359 palynomorphs 
368 per sample (average 317). The highest abundances were shown by Rhizophora, Moraceae-

369 Urticaceae, Quercus and Pinus, while the lowest abundances were shown by Conocarpus,

370 Inga, Bursera and Miconia. From within the 55 identified taxa, only Rhizophora,

371 Cyperaceae, Typha, Asteraceae, Chenopodiaceae, Moraceae-Urticaceae, Alnus, Quercus,

372 Pinus, and Poaceae persisted throughout the entire record. The record was discretized into

373 four main pollen zones (Fig. 4) to facilitate the description of the sedimentary sequence.

374 Pollen zones were defined based on an inspection of the distribution of pollen percentages

375 though time, aiming to identify time periods characterized by relatively stable pollen

376 assemblages.

377

Pollen Zone I (from 1300 to 907 cm blf, c. 7840-6300 cal BP): The sediment showed TC concentrations between 1.84 and $4.78 \%$, with mean of $2.54 \%$, and TN concentrations between 0.06 and $0.20 \%$, with mean $0.10 \%$ (Fig. 2). This zone showed high percentages of

381 Rhizophora (up to 20\%), Moraceae-Urticaceae (up to 50\%), Quercus (up to 20\%), Pinus

382 (up to 50\%), and Poaceae (up to 20\%). Low percentages (less than 5\%) were shown by

383 Avicennia, Amaranthaceae, Croton, Typha, Asteraceae, Chenopodiaceae, Mimosa, Inga, 384 Acacia, Machaerium, Protium, Bursera, Ulmaceae and Miconia (Fig.4).

386 Pollen Zone II (from 907 to 569 cm blf, c. 6300 - 5400 cal BP): The sediment showed 387 highly variable concentrations of both TC and TN (Fig. 2). TC varied between 2.28 and $3889.67 \%$ with mean of $4.6 \%$, whereas TN varied between 0.09 and 0.43 with a mean of $3890.19 \%$. This zone was dominated by Cyperaceae (20\%), Croton (10\%), Typha (20\%), 390 Chenopodiaceae (15\%), Moraceae-Urticaceae (50\%), Alnus ( 6\%), Ulmaceae (10\%), 391 Quercus (20\%), Pinus (50\%) and Poaceae (20\%). Percentages below 5\% were shown by 
Avicennia, Conocarpus, Amaranthaceae, Asteraceae, Mimosa, Inga, Machaerium, Protium, Bursera and Miconia with less than 5\%. The upper part of the zone was characterized by relatively low percentages of Pinus ( 18\%) and a substantial increase of Amaranthaceae, Croton, Typha, Asteraceae, Chenopodiaceae, and Cyperaceae (up to 20\%) (Fig. 4).

Pollen Zone III (from 569 to 280 cm blf, c. 5400 - 3700 cal BP): With lower variability, both TC and TN decreased substantially (Fig. 2). TC varied from 1.14 and $6.31 \%$ with mean of 2.45 , and TN varied between 0.07 and $0.25 \%$ with mean of $0.12 \%$. From 5400 BP Rhizophora abundances began to increase gradually, and Avicennia was less than 5\%. Pinus reached the highest abundances throughout the record (up to 60\%), while Amaranthaceae, Croton, Mimosa, Inga, Machaerium, Bursera, Alnus, Ulmaceae, Moraceae-Urticaceae, and Miconia showed their lowest percentages. Lastly, Typha, Asteraceae, and Chenopodiaceae showed abundances around 10\% (Fig 4).

\section{Pollen Zone IV (from 280 to 0 cm blf, c. 3700 cal BP - Present): TC and TN}

progressively reached high variable concentrations (Fig. 2). TC varied between 0.02 and $7.77 \%$ with mean of $4.45 \%$, and TN varied between 0.01 and $0.36 \%$ with mean of $0.20 \%$. Abundances of Rhizophora and Avicennia reached their highest values (up to $60 \%$ and $10 \%$ respectively), and displayed an increasing trend towards the present. Amaranthaceae, Croton, Typha, Chenopodiaceae, Myrica, Ulmaceae, Quercus, and Pinus abundances decrease up to the present. Meanwhile Acacia, Inga, Machaerium, and Protium presented their highest abundances (up to 10\%) (Fig. 4). 


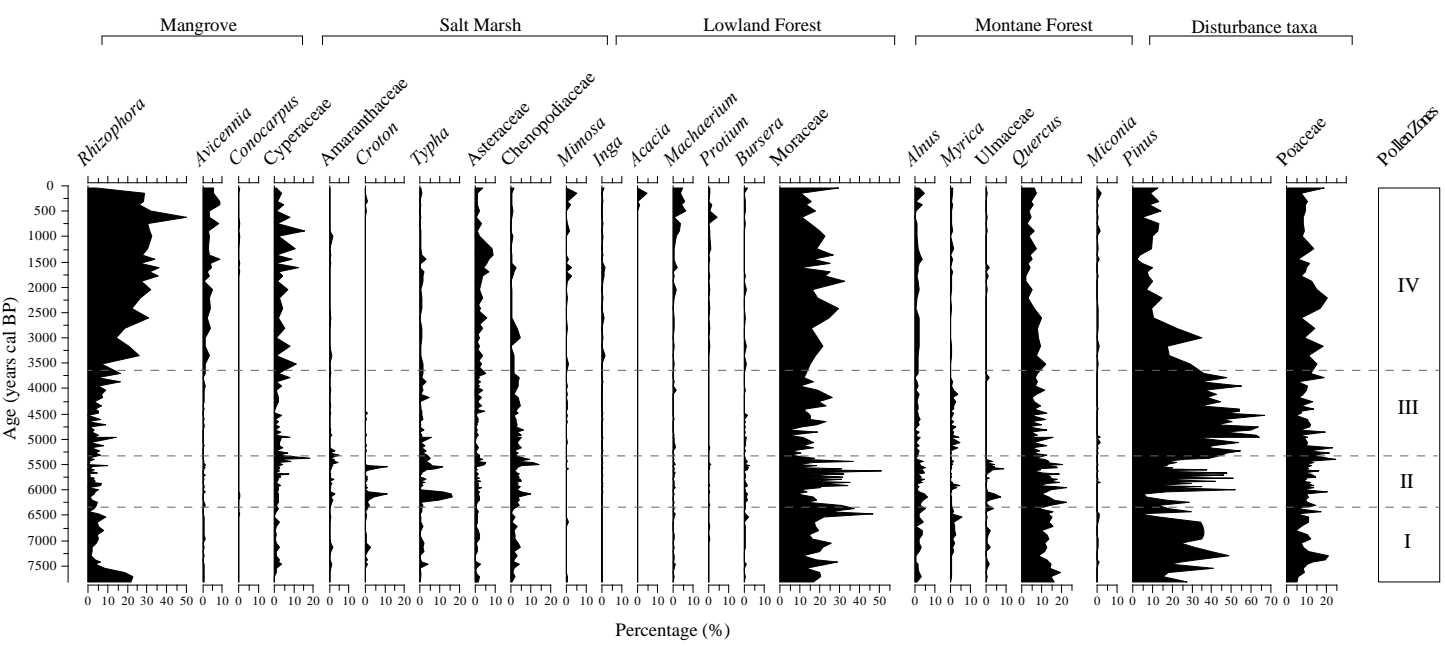

416 Figure 5. Fossil pollen diagram of selected taxa of core MAN15V from La Mancha coastal 417 lagoon. (ecological affinities after Lugo and Snedaker 1974, Ramwell 1972, and Travieso418 Bello 2000).

\subsection{Statistical analyses}

421 The three-dimensional ordination of the modern and fossil pollen samples showed a stress

422 of 0.144 . Negative scores along Axis 1 characterized modern samples, whereas fossil 423 samples were clearly divided into positive (negative) scores for samples older (younger) 424 than $~ 5400$ cal BP (Fig. 5 and 6.B). Along Axis 2, both modern and fossil samples were 425 mostly located between -0.31 and 0.2 , although fossil samples showed positive and negative excursions (Fig. 5). NMDS Axis 3 was characterized by widespread scores for

427 fossil samples and almost exclusively negative scores for modern samples (Appendix 1). The t-test for comparing NMDS scores of modern samples from the northern and 429 southern sub-basins yielded significant differences in terms of Axis 1 and 2, but non430 significant for Axis 3 (Table 2). Given the relatively flat behavior of Axis 2 and the lack of 
431 significance of Axis 3 (Appendix 1), only the first axis of the ordination will be considered 432 for interpretations hereafter.

433

434 Table 2. Comparison of NMDS sample scores in the three axes for modern samples from 435 the northern and southern sub-basins, i.e scores from dense (D) vs. sparse (S) mangrove 436 areas. For the comparison of scores along each axis, $\mathrm{t}$ scores, degrees of freedom corrected 437 for variance differences between samples (d.f.), and p-value are shown.

438

Comparison $\quad \mathrm{t} \quad$ d.f. p-value

\begin{tabular}{llll}
\hline Axis $1_{\mathrm{D}}-$ Axis $1_{\mathrm{S}}$ & -3.5184 & 18 & 0.0026 \\
Axis $2_{\mathrm{D}}-$ Axis $2_{\mathrm{S}}$ & -2.7661 & 26 & 0.0103 \\
Axis $3_{\mathrm{D}}-$ Axis $3_{\mathrm{S}}$ & 1.3831 & 24 & 0.1796 \\
\hline
\end{tabular}

439 


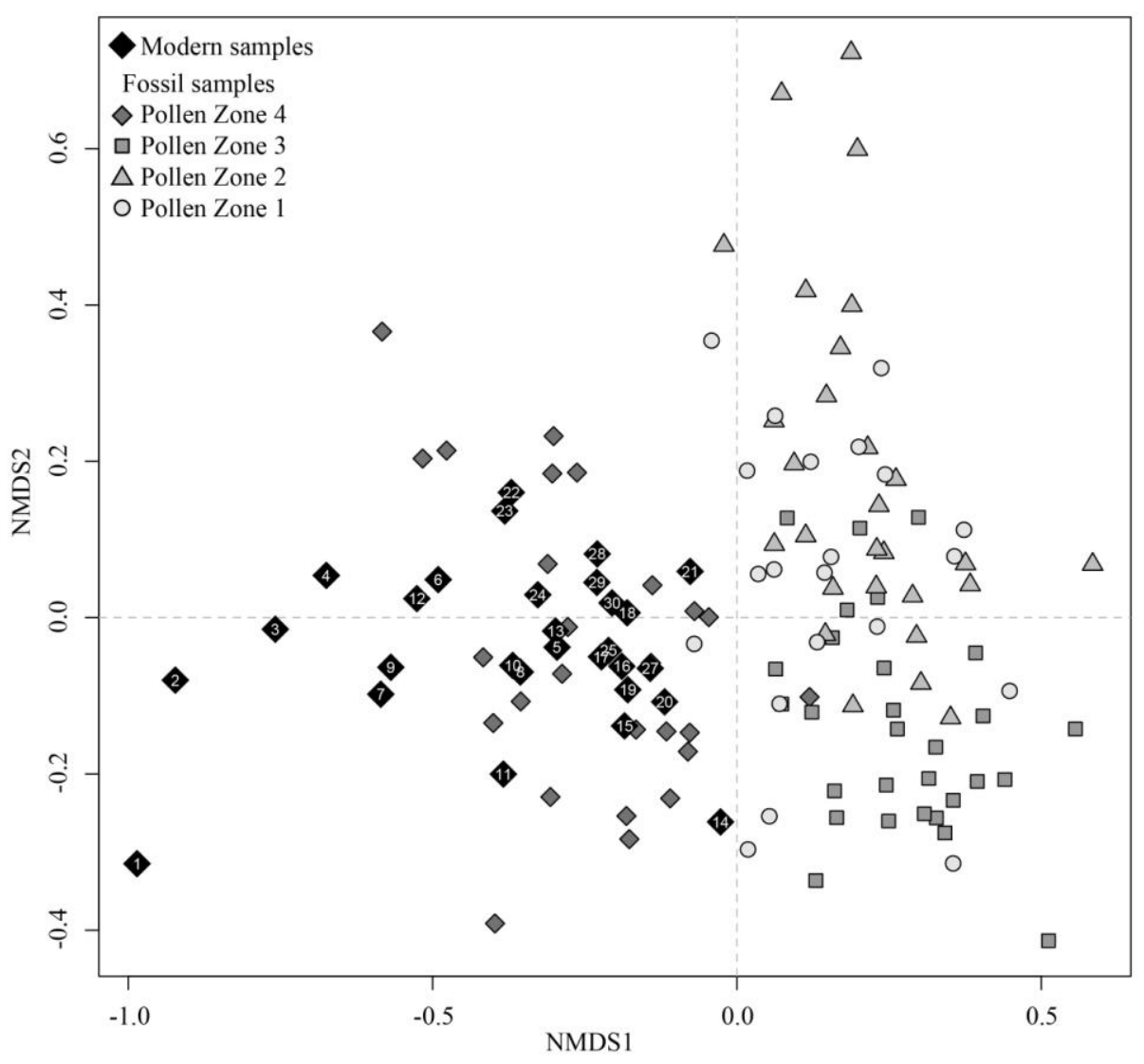

441 Figure 6. Non-metric multidimensional scaling for modern and fossil pollen assemblages

442 from La Mancha lagoon. Modern samples in black diamonds showing sample number,

443 whereas fossil samples were symbol coded according to the declared legend.

\section{5. Discussion}

\subsection{Modern sediments of La Mancha coastal lagoon}

447 Palynological composition of modern samples generally reflected the patterns of modern

448 vegetation, incorporating vegetation elements from the surrounding mangroves and salt

449 marshes (local vegetation), and nearby lowlands and highland forest (regional vegetation).

450 Although the mangroves of La Mancha are dominated by A. germinans over $R$. mangle

451 (Moreno-Casasola, 2006), modern pollen spectra were dominated by the latter (Fig. 3). 
452 Given its pollination mechanism, $R$. mangle produces high amounts of pollen, dominating 453 most of pollen spectra from mangrove forests. Contrastingly, A. germinans is an insect454 pollinated species that produces low amounts of pollen (Hogarth, 2007), resulting in under455 representation of the parental taxon in the pollen spectra where percentages as low as $5 \%$ 456 implying an important share in the standing vegetation. However, the mean representation 457 of $R$. mangle in modern samples from the densely mangrove-forested southern sub-basin $458(\sim 25 \%)$ are low as compared to pollen spectra from stands dominated by this species which 459 have been reported as high as $65 \%$ (e.g. Behling et al., 2001; Urrego et al., 2009). Although 460 C. erecta and L. racemosa are components of the standing forest of La Mancha, they are 461 not represented in the modern pollen spectra probably because of their low production, and 462 also because of their distal position with respect to the sampled water body (Moreno463 Casasola, 2006).

In the southern sub-basin of La Mancha, the high percentages of Rhizophora reflect 465 the relatively good conservation state of the mangroves (Moreno-Casasola, 2006), with the 466 exclusive presence of taxa such as Desmodium, Inga and Protium indicating a well 467 preserved lowland vegetation as well (Franco-Gaviria et al., 2018). Pollen spectra from the 468 northern sub-basin contained lower percentages of Rhizophora, and a substantial 469 representation of regional pollen, possibly coming from the highlands of the catchment 470 basin. Over recent decades, the deleterious effects of human activities on mangrove cover 471 have been more intense around the northern sub-basin of La Mancha lagoon (Lopez472 Portillo et al., 2011; Moreno-Casasola, 2006), reflecting on pollen assemblages where the 473 regional and disturbance elements are better represented (mainly Moraceae-Urticaceae, 474 Myrica, Pinus, Poaceae, and Quercus) (Correa-Metrio et al., 2011; Franco-Gaviria et al., 
475 2018). Although Rhizophora, Moraceae-Urticaceae, Pinus, and Quercus do not dominate

476 the shore vegetation of the most disturbed northern areas, they are represented by pollen

477 percentages above $10 \%$ each (Fig. 3), reflecting the sparse nature of mangrove forests over

478 this area. This finding reflects the widely reported overrepresentation of these taxa in pollen

479 spectra, derived from their high production of pollen and their long-distance pollen

480 dispersal capacity, as reported for species of anemophyllous pollination (e.g. Correa-Metrio

481 et al., 2013; Ellison, 2008; Hooghiemstra et al., 2006; Marchant et al., 2002).

Modern samples were clustered in the NMDS (Fig. 5), implying more consistency among the modern pollen spectra than between modern and fossil samples. This finding demonstrates that the modern heterogeneity of the lagoon does not represent the ecological

485 and environmental variability of the area over the last $\sim 7800$ years. Statistically significant 486 differences between the NMDS Axis 1 scores of pollen assemblages from the two sub487 basins demonstrate that density of mangrove forest cover can be identified though their 488 pollen spectra. Overall, these findings indicate that i) pollen assemblages of La Mancha 489 lagoon are systematically associated with physical and biological attributes of the region at 490 a broad scale (regional vegetation), and ii) pollen spectra are highly sensitive to the modern 491 environmental variability throughout La Mancha lagoon (local vegetation). Thus, as 492 reported for other areas (e.g. Franco-Gaviria et al., 2018; Urrego et al., 2009; Urrego et al., 493 2010), modern pollen assemblages of our studied lagoon provide a robust framework for 494 interpreting our fossil pollen sequence. Higher concentrations of TOC and TN in the southern sub-basin were probably a 496 result of differences in surrounding vegetation and energy of the depositional environment. 497 More vigorous vegetation in the southern sub-basin would produce higher amounts of 
organic matter rich in TOC and TN, whereas the lower energy of the depositional

499 environment would prevent resuspension and, therefore, further oxidation of the sediments

500 (Meyers, 1997). Differently, TIC resulted higher in the northern sub-basin, probably

501 reflecting both higher contribution of marine particulate suspended matter and more

502 oxidation of organic components (Bouillon et al., 2003). Overall, C and N analyses are

503 consistent with higher organic matter storage in the sediments of the lagoon where

504 mangrove forests are well preserved. The relationships that were found between the

505 different components of $\mathrm{C}$ and $\mathrm{N}$ demonstrate that in the modern setting of La Mancha,

506 TOC is the main component of TC. Although these relationships cannot be extrapolated to

507 the fossil record, they demonstrate that $\mathrm{TN}$ is a good proxy for organic matter, and

508 therefore it is used to offer further support to our pollen-based reconstruction of past

509 environmental dynamics.

\subsection{Vegetation history of La Mancha Lagoon}

512 The pollen record of La Mancha lagoon reflects the complexities associated with the

513 multiple factors that have intervened in the development toward the modern biotic and

514 abiotic systems. Whereas highly variable abundances of regional vegetation suggest

515 variability in freshwater input by precipitation and tributaries to the lagoon system, pollen

516 from mangroves together with herbaceous vegetation offer insights into the successional

517 patterns and development of the local vegetation (Urrego et al., 2013; Urrego et al., 2018).

518 Additionally, the constant presence of marine shells through the sedimentary record (Fig. 2)

519 demonstrates a permanent marine influence through the last $\sim 7,800$ year. Together, these

520 indicators illustrate the intimate interaction between sea levels and regional fresh water 
521 inputs (precipitation, sediments) that ultimately regulates the colonization, establishment,

522 and development of mangrove ecosystems in the area. According to our pollen and

523 geochemical data, the history of the vegetation that surrounds the lagoon and therefore the

524 regional environmental history could be summarized in four main stages that will be

525 discussed below.

526 From c.7800 to 6300 cal BP: sea-water flooding of valleys

527 Through this time period, the mud-water interface was between 13 and $9 \mathrm{~m}$ below the

528 modern surface, which today is at sea level. At the same time, average sea level was

529 between 9 and $5 \mathrm{~m}$ below modern. The difference between mud-water interface depth and

530 sea level can only be accounted by lagoon water depth, which was $\sim 4 \mathrm{~m}$ below sea level

531 (Fig. 6A). La Mancha Hill, an andesitic rock of Neogene origin (Moreno-Casasola, 2006;

532 Geissert Kientz, 1999) (Fig. 1), probably acted as a barrier that protected the depositional

533 environment from the erosive energy of the waves and winds. Through this period, even

534 though sedimentation rates at La Mancha ( 3.04 mm/year) were lower than the inferred

535 rate of sea-level increase, they are among the highest through the record. High rates of both

536 regional sea-level rise and sedimentation at La Mancha are likely a result of the regional

537 geologic instability that characterized the conformation of the modern Gulf of Mexico in its

538 final stages, up to $5000 \mathrm{cal}$ BP (Davis, 2011). As sea level increased through the

539 deglaciation and the early Holocene, sea-water flooded coastal plains and valleys at a speed

540 that surpassed the accumulation of continental sediments. Thus, the lacustrine basin of La

541 Mancha was probably deeper than modern, impeding the establishment of mangrove forests

542 (Fig. 6C). A peak of Rhizophora from the bottom of the record to 7500 cal BP (Fig. 4)

543 probably shows the colonization of mangroves during the initial stages of the lagoon and 
544 the sea-water flooding, which were subsequently displaced by the formation of a deep545 water body.

546 In México, Pinus populations thrive under early post-disturbance successional

547 stages, or under conditions that are not optimal for other taxa (Metcalfe et al., 2000;

548 Ramirez-Marcial et al., 2001). Thus, the persistence of Pinus in high percentages from the

549 bottom of the record to $\sim 6500$ cal BP (Fig. 5) indicates that regional conditions were likely

550 dry, an interpretation that is further supported by the lowest concentrations of TN (Fig. 7)

551 and therefore of organic matter. These dry conditions probably played a central role at

552 maintaining sedimentation rates that did not offset sea-level rise, impeding the

553 establishment of mangrove forests, as demonstrated by the NMDS Axis 1 scores that were

554 outside the envelope defined by modern samples (Fig. 7C).

555 


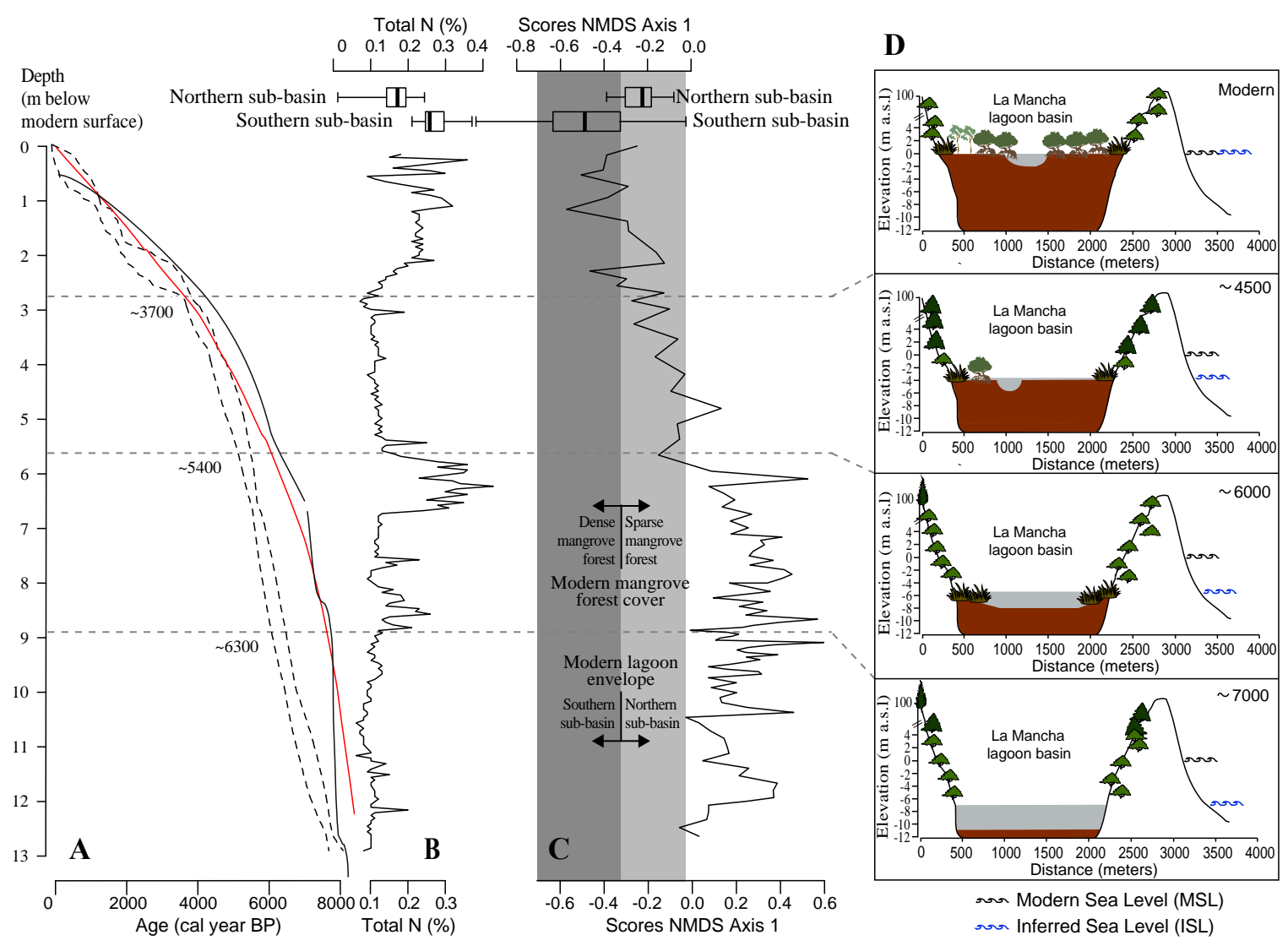

557 Figure 7. Environmental history of La Mancha Lagoon through the last 7,800 years. A.

558 Age-depth model of core MAN15V from La Mancha Lagoon (dashed lines show 95\%

559 confidence interval), compared with sea level rise curves for the Caribbean (red line,

560 Toscano and Macintyre, 2003) and the northern Gulf of Mexico (black solid line, Milliken

561 and Anderson, 2008). B. Sedimentary total nitrogen content (\%); boxplots illustrate total

562 nitrogen in modern samples form the northern (up) and southern (down) sub-basins of the

563 lagoon (whiskers show minimum and maximum scores). C. NMDS Axis 1 scores through

564 time; boxplots illustrate scores of modern samples; scores of the modern environmental

565 envelope represented by modern samples are highlighted in grey; scores of the interquartile

566 range of samples from the well preserved southern sub-basin are in dark grey. D. Schematic

567 development of La Mancha Lagoon, illustrated at 7,000, 6000, 4,500 cal BP, and Modern. 
570 Whereas the rate of sea-level rise started to decline through this period, sedimentation rates

571 at La Mancha remained high (3.86 mm/yr, Fig. 6). This phenomenon could be explained by

572 two critical factors: i) following the reported deceleration of sea-level rise at $\sim 7000$ cal BP

573 (Toscano and Macintyre, 2003), sand bars started accumulating at the mouth of coastal

574 lagoons (Davis, 2011), providing a more stable plain for sediment accumulation at La

575 Mancha; and ii) a substantial decrease in the percentages of Pinus, and an increase of

576 montane forest taxa (e.g. Alnus, Quercus, and Ulmaceae) indicate wetter conditions that

577 would be in turn associated with higher river sediment discharge. These regional wetter

578 conditions could be related to the final stages of the Holocene Thermal Maximum, which

579 was in general characterized by higher than present precipitation and temperature in the

580 Northern Hemisphere (Renssen et al., 2009).

The lagoon became shallower, and the development of muddy shores is evidenced

582 by high percentages of salt marsh vegetation (Fig. 5), and high accumulation of organic

583 matter revealed by the increasing TN (Fig. 7B). This state of local vegetation and the high

584 accumulation of organic matter suggest the closing of the ephemeral mouth, probably

585 caused by lower energy associated with the shallowing of the lagoon, together with the

586 intensification of the wind currents, and sea level changes reported for the Gulf of Mexico

587 and the Caribbean (Balsille and Donoghue, 2004; González and Dupont, 2009; Urrego et

588 al., 2013; Wooller et al., 2007). Pollen spectra suggest the early stages of a successional 589 pattern of mangrove vegetation associated with the marine transgression, although NMDS 
590 Axis 1 sample scores demonstrate that mangrove forests were not established yet near the

591 location where the core was retrieved.

592 From c. 5400 to 3700 BP: A regional drought

593 Whereas the rate of sea-level rise continued to decrease, relatively high sedimentation rates

594 were evident in La Mancha sequence up to 5000 cal BP, when apparently the rates of

595 sediment deposition in the lagoon and those of sea level rise became similar (Fig. 6A).

596 Such equilibrium between sediment deposition and sea-level rise implies the definition of a

597 coastal erosive baseline that allowed the deposition of sand in the coast by the northerly

598 currents during the dry season, creating the sandbar that dams the lagoon. Differently,

599 during the wet season, the fluvial input would have the capacity to erode the sandbar,

600 opening the direct contact between the lagoon and the sea and, thus, resulting in the modern

601 seasonal flood cycle. During the dry season, the coastal bar would be closed by the action

602 of the waves and the prevailing winds, whereas during the rainy season the bar would be

603 opened by the energy of the fresh water discharge. The lagoon thus became a shallow water

604 body $\left(\mathrm{z}_{\max } \sim 1 \mathrm{~m}\right)$ mostly protected from the energy of the waves by La Mancha hill (Fig.1),

605 and subjected to seasonal tidal and climatic fluctuations.

606 From c. 5400 to $3700 \mathrm{cal} \mathrm{BP}$, the recurrent drainage of fresh water into the sea

607 probably created a series of channels giving the lagoon a physiography very similar to

608 modern. However, according to the NMDS scores, vegetation at that time resembled the

609 northern sub-basin today (Fig. 6B), an area characterized by poorly developed sparse

610 mangrove stands. Thus, vegetation assemblages from this period were a result of

611 suboptimal environmental conditions for mangrove forest development. High percentages

612 of Pinus (up to 60\%) through this period suggest that there was a regional drought in place, 
613 which likely maintained high substrate salinity by reducing freshwater river discharge to

614 the lagoon. Thus, local vegetation consisted of a mixture of sparse mangrove trees with

615 some salt marshes species, and a slow increase of mangrove pollen because of the

616 prevailing dry conditions (Fig. 4). Although anthropogenic influence cannot be discarded as

617 a plausible explanation for the sparse mangrove vegetation, the inference of a regional

618 drought is supported by similar reports from Lake Petén Itzá between 4500 up to 3000

619 cal BP, Lake Tzib (Quintana Roo) at 3500 cal BP (Carrillo-Bastos et al., 2010; Mueller et

620 al., 2010), and also in the Cariaco Basin record, with a trend from 5400 up to the present

621 (Haug et al., 2001). Furthermore, the abrupt decrease of TN and its linear trend towards

622 even lower concentrations (Fig. 7B) evidence rather oxidizing conditions, an environmental

623 process that is difficult to explain from the perspective of human occupation.

624

625 From c. 3700 cal BP to Present: the establishment of modern mangrove forests

626 Mangrove pollen taxa showed the highest percentages (Fig. 5), reflecting an environment of

627 relative stability where the exchange of saline and fresh water, and the input of sediments

628 were balanced, producing an increase of mangrove forest biomass (Krauss et al., 2008).

629 These conditions provided consolidated clay sediments, where as indicated by the NMDS

630 scores, mangrove forests developed into mature forest stands of Rhizophora and Avicennia.

631 Increasing concentrations of TN (Fig. 7B) indicate high accumulation of organic matter

632 probably associated with the establishment of the mangrove forest (Bouillon et al. 2003).

633 Sea level continued to increase at slower rates (Balsille and Donoghue, 2004) that were

634 matched by the rate of sediment accumulation in La Mancha ( $\sim 0.92 \mathrm{~mm} / \mathrm{yr}$ on average).

635 These more stable conditions for coastal ecosystems have been reported for other localities 
636 in the Caribbean coinciding with other records (Urrego et al., 2013), where mangrove

637 forests developed under a relatively stable sedimentation rate (1.09 to $0.89 \mathrm{~mm} / \mathrm{yr}$ ).

Pinus and salt marsh pollen in La Mancha showed substantial decreases caused by

639 wetter conditions and higher representation of local mangrove pollen, implying a lower

640 regional influence on pollen spectra, and the continuation of the successional processes that

641 led to the establishment of the mangrove forest (González and Dupont, 2009). At this stage,

642 the lagoon seems to have reached its modern configuration, with influences from local

643 processes like the annual opening of the ephemeral mouth, fluctuating floods of salt water,

644 input of fresh water from the streams, and anthropogenic activities (Moreno-Casasola,

645 2006). Indeed, the sharp decrease of Rhizophora is likely reflecting the terrestrialization of

646 the cored site, which today is occupied by an Avicennia germinans forest that floods only

647 when the ephemeral mouth is closed and the lagoon reaches its maximum water level

648 through the year. This latter observation is further supported by the high variability of TN

649 concentrations towards the top of the record.

650

\section{6. Conclusion}

652 The sedimentary record of La Mancha lagoon encompasses the history of local and regional

653 environmental conditions through the last $\sim 8,000$ years, including the establishment of

654 modern mangrove forest along the coast of Veracruz. The record shows the regional

655 context under which the coastal lagoon formed, showing the transformation of the lagoon

656 from a water body with permanent communication with the sea to the modern seasonally

657 closed system. When sea level rise rates were higher than the rates of sediment infill of the

658 lagoon's basin, the depositional environment was under sea level and pollen assemblages 
were dominated by regional taxa. The ecological succession towards the establishment of 660 mangrove forest started at $\sim 6,300$ cal BP, but mangrove forests were sparse, resembling

661 those of the modern northern sub-basin because of two main reasons: i) the water column 662 was relatively deep and sedimentary plains for mangrove establishment were likely narrow, 663 and ii) a regional drought lasting from $\sim 5400$ to 3700 BP probably caused extremely high 664 substrate salinity that impeded mangrove forests expansion. Dense mangrove forests like 665 those that occupy the southern sub-basin today established around $\sim 3500 \mathrm{BP}$, and have 666 dominated the area ever since.

667 The matching of lagoon sediment and sea levels at $\sim 4000$ cal BP was likely 668 associated with the development of the seasonally open mouth. This pairing of lagoon 669 sedimentary accumulation and sea levels defined the latter as the base level for erosion, 670 allowing the accumulation of material during the dry season, and therefore the formation of 671 a damming bar, which would eventually be open during the rainy season owing to the 672 increased freshwater discharge. Concomitant to this process would be the linear erosion of 673 channels through the sedimentary deposit, conforming the modern geomorphology of the 674 area. The establishment of the mangrove forest implied a substantial increase of 675 sedimentary organic matter, highlighting the role of these ecosystems at storing carbon.

676 Overall, our record demonstrates the complexity of the interactions between local and 677 regional factors in the development and evolution of both coastal geomorphology and 678 ecosystems. 
683 Innovación Tecnológica PAPIIT-UNAM [grant number IN107716], and Consejo Nacional

684 de Ciencia y Tecnología [grant number 256406]. Alex Correa-Metrio was supported by

685 Programa de Apoyos para la Superación del Personal Académico de la UNAM (PASPA).

686

687

688

689

690

691

692

693

694

695

696

697

698

699

700

701

702

703

704

705

706

707

708

709

710

711

712

713

714

715

716

717

718

719

\section{References}

Ball, M.C., 2002. Interactive effects of salinity and irradiance on growth: implications for mangrove forest structure along salinity gradients. Trees, 16, 126-139.

Balsillie, J.H., Donoghue, J.F., 2004. High resolution sea-level history for the Gulf of Mexico since the last glacial maximum. Florida Geological Survey.

Behling, H., Cohen, M.C.L., Lara, R.J., 2001. Studies on Holocene mangrove ecosystems dynamics of the Braganca Peninsula in north-eastern Para, Brazil. Palaeogeography, Palaeoclimatology, Palaeoecology, 167, 225-242.

Blaauw, M., Christen, J.A., 2011. Flexible paleoclimate age-depth models using an autoregressive gamma process. Bayesian Analysis, 6, 457-474.

Bouillon, S. et al., 2008. Mangrove production and carbon sinks: a revision of global budget estimates. Global Biogeochemical Cycles, 22.

Bouillon, S., Dahdouh-Guebas, F., Rao, A., Koedam, N., Dehairs, F., 2003. Sources of organic carbon in mangrove sediments: variability and possible ecological implications. Hydrobiologia, 495, 33-39.

Bush, M.B., 2002. On the interpretation of fossil Poaceae pollen in the lowland humid neotropics. Palaeogeography, Palaeoclimatology, Palaeoecology, 177, 5-17.

Carrillo-Bastos, A., Islebe, G.A., Torrescano-Valle, N., González, N.E., 2010. Holocene vegetation and climate history of central Quintana Roo, Yucatan Peninsula, Mexico. Review of Palaeobotany \& Palynology, 160, 189-196.

Colinvaux, P., de Olivera, P.E., Moreno, P.J.E., 1999. Amazon Pollen Manual and Atlas. Harwood Academic Publishers, Amsterdam.

Correa-Metrio, A., Bush, M.B., Lozano-García, M.S., Sosa-Nájera, S., 2013. Millennial-scale temperature change velocity in the continental northern Neotropics. PLoS ONE, 8, e81958.

Correa-Metrio, A., Bush, M.B., Pérez, L., Schwalb, A., Cabrera, K.R., 2011. Pollen distribution along climatic and biogeographic gradients in northern Central America. The Holocene, 21, 681692.

Davis, R.A., 2011. Sea-level change in the Gulf of Mexico. Texas A\&M University Press, Corpus Christi.

Ellison, J.C., 1989. Pollen analysis of mangrove sediments as a sea-level indicator: assessment from Tongatapu, Tonga. Palaeogeography, Palaeoclimatology, Palaeoecology, 74, 327-341. 
Ellison, J.C., 2008. Long-term retrospection on mangrove development using sediment cores and pollen analysis: a review. Aquatic Botany, 89, 93-104.

Faegri, K., Iversen, J., 1989. Textbook of pollen analysis. 4th ed. Wiley, Chichester.

Faith, D.P., Minchin, P.R., Belbin, L., 1987. Compositional dissimilarity as a robust measure of ecological distance. Vegetatio, 69, 57-68.

FAO-UNEP, 2007. The world's mangroves 1980-2005. FAO Forestry Paper.

Feller, I.C., Friess, D.A., Krauss, K.W., Lewis, R.R., 2017. The state of the world's mangroves in the 21st century under climate change. Hydrobiologia, 803, 1-12.

Franco-Gaviria, F. et al., 2018. The human impact imprint on the modern pollen spectra of the Maya lands. Boletín de la Sociedad Geológica Mexicana, 70, 61-78.

Geissert Kientz, D., 1999. Regionalización geomorfológica del estado de Veracruz. Investigaciones geográficas, 23-47.

Gilman, E.L., Ellison, J., Duke, N.C., Field, C., 2008. Threats to mangroves from climate change and adaptation options: a review. Aquatic botany, 89, 237-250.

González, C., Dupont, L.M., 2009. Tropical salt marsh succession as sea-level indicator during Heinrich events. Quaternary Science Reviews, 28, 939-946.

González, C., Urrego, L.E., Martínez, J.I., Polanía, J., Yokoyama, Y., 2010. Mangrove dynamics in the southwestern Caribbean since the 'Little Ice Age': A history of human and natural disturbances. The Holocene, 20, 849-861.

Hamilton, S.E., Casey, D., 2016. Creation of a high spatio-temporal resolution global database of continuous mangrove forest cover for the 21st century (CGMFC-21). Global Ecology and Biogeography, 25, 729-738.

Haug, G.H., Hughen, K.A., Sigman, D.M., Peterson, L.C., Rohl, U., 2001. Southward migration of the Intertropical Convergence Zone through the Holocene. Science, 293, 1304-1308.

Hogarth, P.J., 2015. The biology of mangroves and seagrasses. Oxford University Press, Oxford.

Hooghiemstra, H., Lézine, A.M., Leroy, S.A.G., Dupont, L., Marret, F., 2006. Late Quaternary palynology in marine sediments: A synthesis of the understanding of pollen distribution patterns in the NW African setting. Quaternary International, 148, 29-44.

Kjerfve, B., 1994. Coastal lagoon processes. Elsevier, Amsterdam.

Krauss, K.W. et al., 2008. Environmental drivers in mangrove establishment and early development: a review. Aquatic Botany, 89, 105-127.

Lankford, R.R., 1977. Coastal lagoons of Mexico their origin and classification, Estuarine Processes: Circulation, Sediments, and Transfer of Material in the Estuary. Elsevier, pp. 182-215.

Legendre, P., Legendre, L., 2012. Numerical Ecology. Elsevier Scientific, Oxford.

López-Portillo, J., 2011. Atlas de las costas de Veracruz: manglares y dunas [costeras]. Gobierno del Estado de Veracruz, Secretaría de Educación, Xalapa.

Lugo, A.E., Snedaker, S.C., 1974. The ecology of mangroves. Annual review of ecology and systematics, 5, 39-64.

Marchant, R. et al., 2002. Distribution and ecology of parent taxa of pollen lodged within the Latin American Pollen Database. Review of Palaeobotany and Palynology, 121, 1-75.

Méndez Linares, A., López-Portillo, J., Hernández-Santana, J., Pérez, M.O., Orozco, O.O.J.C., 2007. The mangrove communities in the Arroyo Seco deltaic fan, Jalisco, Mexico, and their relation with the geomorphic and physical-geographic zonation. 70, 127-142.

Metcalfe, S.E., O'Hara, S.L., Caballero, M., Davies, S.J., 2000. Records of Late Pleistocene-Holocene climate change in Mexico- a review. Quaternary Science Reviews, 19, 699-721.

Meyers, P.A., 1997. Organic geochemical proxies of paleoceanographic, paleolimnologic, and paleoclimatic processes. Organic geochemistry, 27, 213-250. 
Milliken, K., Anderson, J.B., Rodriguez, A.B., 2008. A new composite Holocene sea-level curve for the northern Gulf of Mexico. Geological Society of America Special Paper, 443, 1-11.

Moreno-Casasola, P., 2006. Entornos veracruzanos: la costa de La Mancha, Instituto de Ecología, A.C., Xalapa, Veracruz, Mexico.

Mueller, A.D. et al., 2010. Late Quaternary palaeoenvironment of northern Guatemala: evidence from deep drill cores and seismic stratigraphy of Lake Petén Itzá. Sedimentology, 57, 12201245.

Parkinson, R.W., DeLaune, R.D., White, J.R., 1994. Holocene sea-level rise and the fate of mangrove forests within the wider Caribbean region. Journal of Coastal Research, 10771086.

Ramírez-Marcial, N., González-Espinosa, M., Williams-Linera, G., 2001. Anthropogenic disturbance and tree diversity in montane rain forests in Chiapas, Mexico. Forest Ecology Management, 154, 311-326.

Ranwell, D.S., 1972. Ecology of salt marshes and sand dunes, Ecology of salt marshes and sand dunes. Chapman and Hall, London, pp. 200 pp.

Reimer, P.J. et al., 2013. IntCal13 and Marine13 radiocarbon age calibration curves $0-50,000$ years cal BP. Radiocarbon, 55, 1869-1887.

Renssen, H. et al., 2009. The spatial and temporal complexity of the Holocene thermal maximum. Nature Geoscience, 2, 411-414.

Richardson, D.M., 1998. Ecology and Biogeography of Pinus. Cambridge University Press, Cambridge.

Rzedowski, J., 2006. Vegetación de México. Comisión Nacional para el Conocimiento y Uso de la Biodiversidad, México D.F., pp. 504 pp.

Servicio Meteorologico Nacional, 2018. Normales climatológicas, Estado de Veracruz, Estación La Mancha (online,last accessed June 2018).

Soares, M., 2009. A conceptual model for the responses of mangrove forests to sea level rise. Journal of Coastal Research, 267-271.

Suárez, J.A., Urrego, L.E., Osorio, A., Ruiz, H.Y., 2015. Oceanic and climatic drivers of mangrove changes in the Gulf of Urabá, Colombian Caribbean. Latin American Journal of Aquatic Research, 43.

Thom, B.G., 1967. Mangrove ecology and deltaic geomorphology: Tabasco, Mexico. The Journal of Ecology, 301-343.

Thorhaug, A., Poulos, H.M., López-Portillo, J., Ku, T.C., Berlyn, G., 2017. Seagrass blue carbon dynamics in the Gulf of Mexico: Stocks, losses from anthropogenic disturbance, and gains through seagrass restoration. Science of The Total Environment, 605, 626-636.

Toscano, M.A., Macintyre, I.G., 2003. Corrected western Atlantic sea-level curve for the last 11,000 years based on calibrated $14 \mathrm{C}$ dates from Acropora palmata framework and intertidal mangrove peat. Coral reefs, 22, 257-270.

Travieso-Bello, A., 2000. Biodiversidad del paisaje costero de La Mancha, Actopan, Veracruz. Instituto de Ecología, Xalapa.

Urrego, L.E., Bernal, G., Polanía, J., 2009. Comparison of pollen distribution patterns in surface sediments of a Colombian Caribbean mangrove with geomorphology and vegetation. Review of Palaeobotany and Palynology, 156, 358-375.

Urrego, L.E., Correa-Metrio, A., González, C., Castaño, A.R., Yokoyama, Y., 2013. Contrasting responses of two Caribbean mangroves to sea-level rise in the Guajira Peninsula (Colombian Caribbean). Palaeogeography, Palaeoclimatology, Palaeoecology, 370, 92-102. 
813

814

815

816

817

818

819

820

821

822

823

824

825

826

827

828

829

830
Urrego, L.E., Correa-Metrio, A., González-Arango, C., 2018. Colombian Caribbean mangrove dynamics: anthropogenic and environmental drivers. Boletín de la Sociedad Geológica Mexicana, 70, 133-145.

Urrego, L.E., González, C., Urán, G., Polanía, J., 2010. Modern pollen rain in mangroves from San Andres Island, Colombian Caribbean. Review of Palaeobotany and Palynology, 162, 168182.

Valiela, I., Bowen, J.L., York, J.K., 2001. Mangrove Forests: One of the World's Threatened Major Tropical Environments. Bioscience, 51, 807-815.

Vovides, A.G. et al., 2014. Morphological plasticity in mangrove trees: salinity-related changes in the allometry of Avicennia germinans. Trees, 28, 1413-1425.

Ward, R.D., Friess, D.A., Day, R.H., MacKenzie, R.A., 2016. Impacts of climate change on mangrove ecosystems: a region by region overview. Ecosystem Health Sustainability, 2, e01211.

Williams-Linera, G., 2002. Tree species richness complementarity, disturbance and fragmentation in a Mexican tropical montane cloud forest. Biodiversity \& Conservation, 11, 1825-1843.

Wooller, M.J., Morgan, R., Fowell, S., Behling, H., Fogel, M., 2007. A multiproxy peat record of Holocene mangrove palaeoecology from Twin Cays, Belize. The Holocene, 17, 1129-1139.

Zar, J.H., 1999. Biostatistical Analysis. 4th ed. Prentice-Hall, Upper Saddle River, NJ. 
- During the mid Holocene, sedimentation rates were lower than sea level rise rates

- Modern barrier-lagoon systems of the Gulf of Mexico appeared 5000 years ago

- A drought between 5400 and 3700 years ago impeded mangrove forest establishment

- Modern coastal lagoons of the western Gulf of Mexico established 3700 years ago

- The establishment of mangroves caused an increase of sedimentary organic matter 
Table 1. Radiocarbon dates of core MAN15V from La Mancha coastal lagoon. Depths in cm below lagoon floor (blf). Ages calibrated after the IntCal13 curve (Reimer et al., 2013).

\begin{tabular}{lcccc}
\hline Laboratory code & Depth (cm blf) & ${ }^{14}$ C Age & Error & $\begin{array}{c}\text { Calibrated age } \\
\text { (95\% range; cal BP) }\end{array}$ \\
\hline UBA-34340 & 109 & 1290 & 24 & $1181-1283$ \\
Beta-440367 & 175 & 1880 & 30 & $1730-1883$ \\
UBA-34341 & 282 & 3447 & 26 & $3637-3826$ \\
Beta-440368 & 373 & 3970 & 30 & $4300-4523$ \\
UBA-34342 & 564 & 4732 & 41 & $5326-5584$ \\
Beta-437078 & 649 & 4770 & 30 & $5334-5588$ \\
UBA-34343 & 979 & 5624 & 41 & $6312-6482$ \\
Beta-437079 & 1249 & 6700 & 30 & $7508-7616$ \\
\hline
\end{tabular}




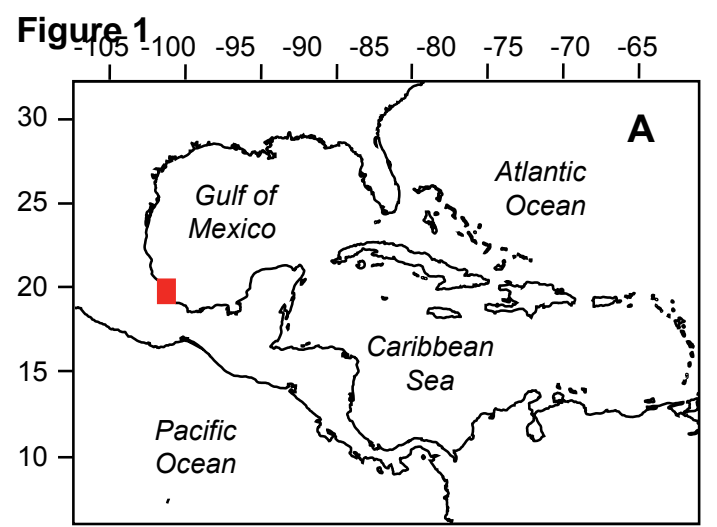

8
ர
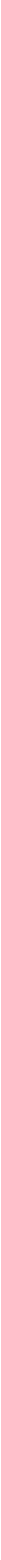
Figure $A$

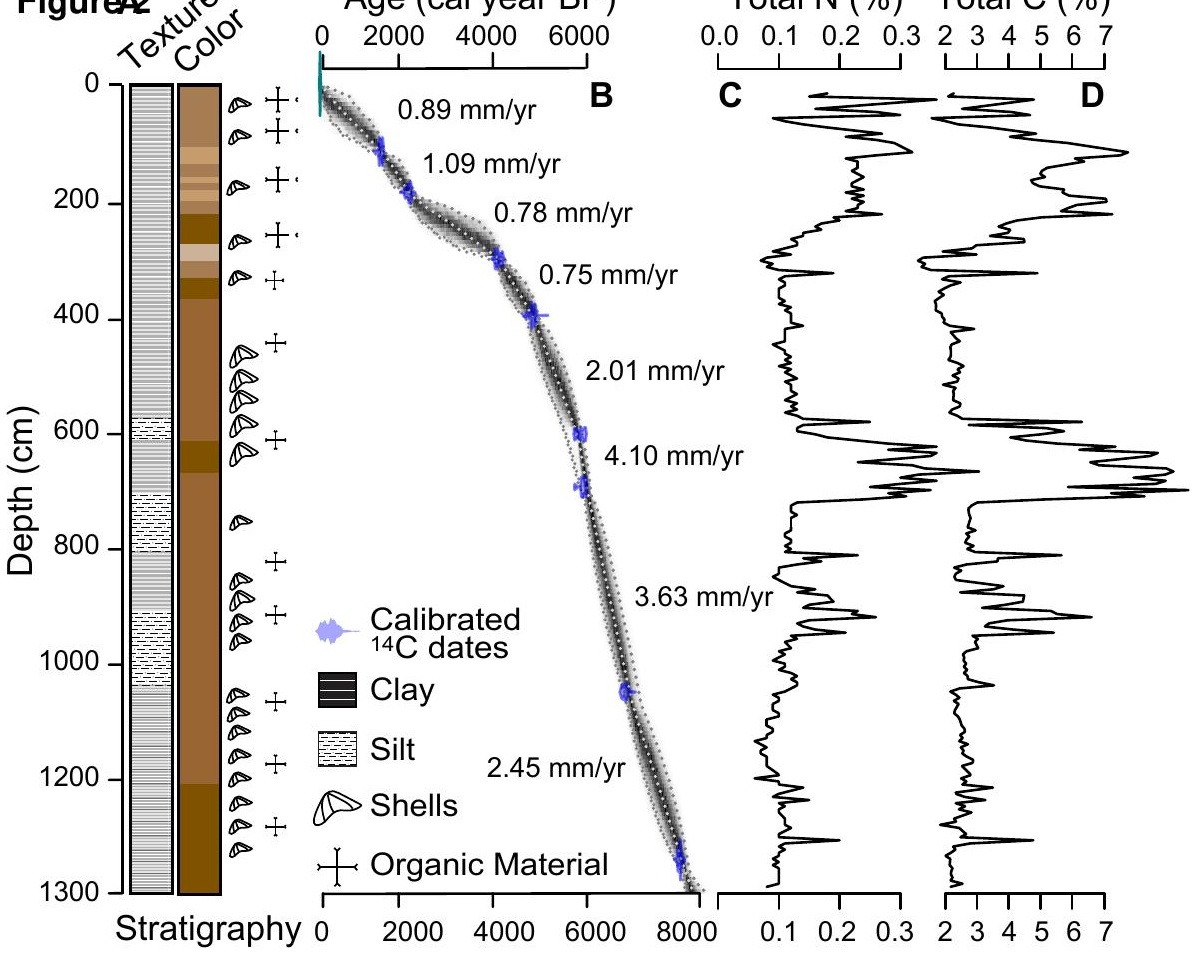




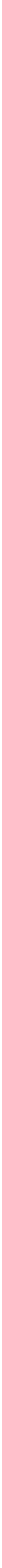




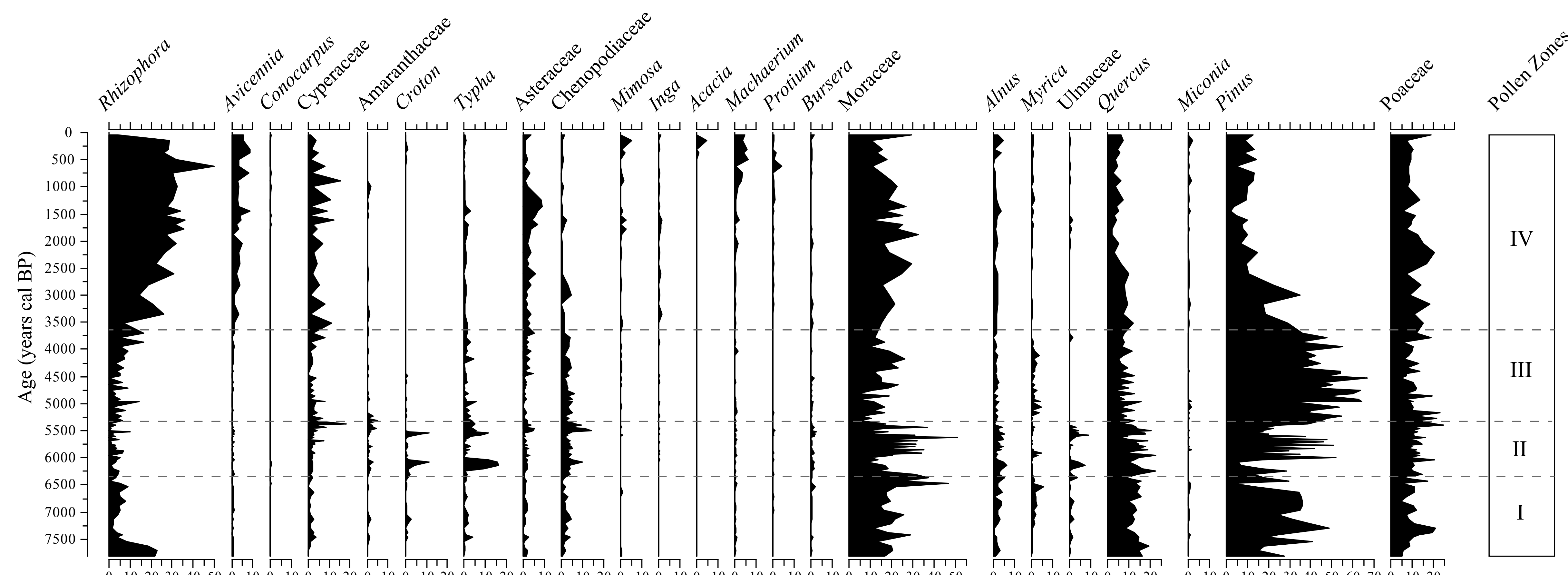


Depth

(m below

Northern sub-basin modern surface)

Southern sub-basin

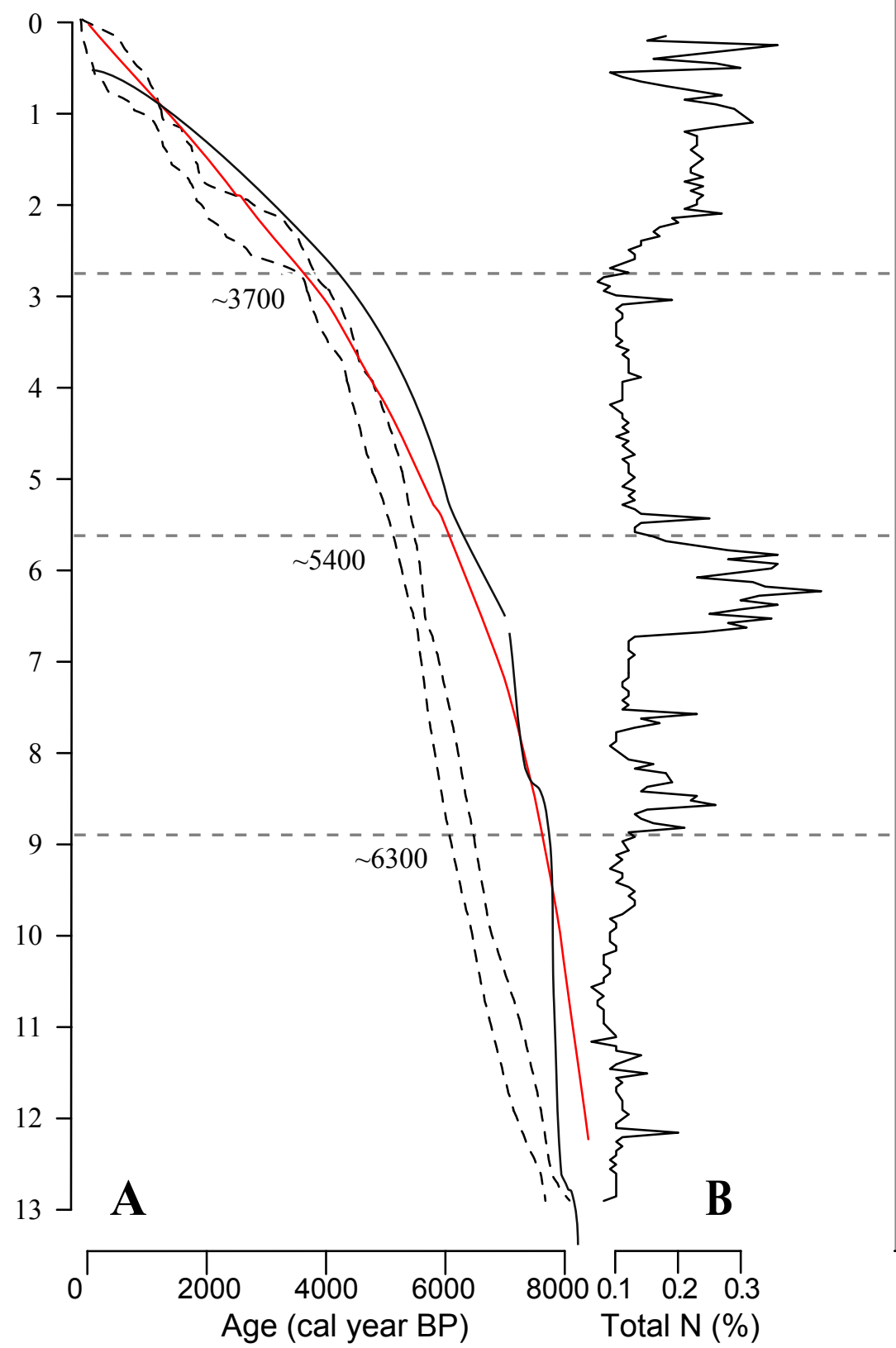

\begin{tabular}{ccccc}
0.8 & -0.6 & -0.4 & -0.2 & 0.0 \\
\hline & $\mid$ & $\mid$
\end{tabular}

D

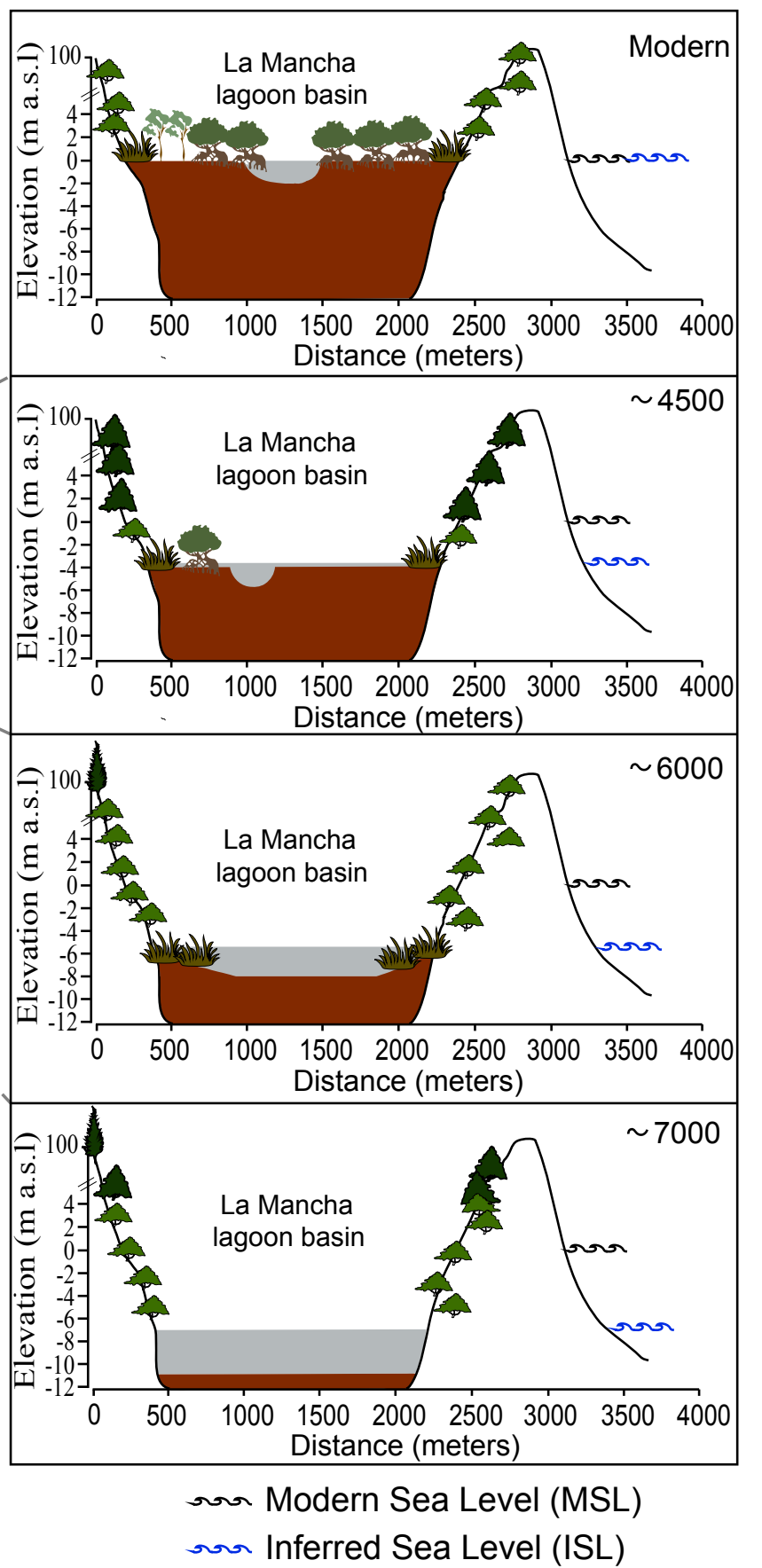


Figure 1. Study area. A. Location of La Mancha lagoon in the continental context. B. Locations sampled for modern and fossil sediments in the local context of La Mancha coastal lagoon; elevation contours are shown in increments of $20 \mathrm{~m}$ asl (solid black lines), whereas a basic bathymetry based on field observations is shown as blue contours. C. Monthly precipitation (blue bars), evapotranspiration (gray bars), and monthly mean temperature (black line with dots) at La Mancha Meteorological Station (Servicio Meteorologico Nacional, 2018) D. Topographic representation of La Mancha coastal lagoon.

Figure 2. Core MAN15V from La Mancha coastal lagoon. A. Stratigraphy of the sedimentary sequence: texture (left), color (right), and organic and shell content. B. Agedepth model; calibrated ages (blue silhouettes), 95\% confidence intervals in grey (darker colors indicate higher probability), and sedimentation rates (mm/yr). C and D. Percentage of total nitrogen and total carbon content (TN and TC, respectively).

Figure 3. Pollen diagram of selected taxa from mud-water interface samples from La Mancha coastal lagoon. Ecological affinities after Lugo and Snedaker (1974), Ramwell (1972), and Travieso-Bello (2000). Samples are ordered from South to North with samples from the southern (northern) sub-basin highlighted in dark (light) grey.

Figure 4. Content (\%) of carbon and nitrogen in the modern samples of La Mancha coastal lagoon. Total C content (TC) discriminated into inorganic and organic fractions (TIC and 
TOC), and total $\mathrm{N}$ content (TN). Comparisons among sedimentary attributes are shown in the right side panels (biplots and correlation coefficients with their significance).

Figure 5. Fossil pollen diagram of selected taxa of core MAN15V from La Mancha coastal lagoon. (ecological affinities after Lugo and Snedaker 1974, Ramwell 1972, and TraviesoBello 2000).

Figure 6. Non-metric multidimensional scaling for modern and fossil pollen assemblages from La Mancha lagoon. Modern samples in black diamonds showing sample number, whereas fossil samples were symbol coded according to the declared legend.

Figure 7. Environmental history of La Mancha Lagoon through the last 7,800 years. A. Age-depth model of core MAN15V from La Mancha Lagoon (dashed lines show 95\% confidence interval), compared with sea level rise curves for the Caribbean (red line, Toscano and Macintyre, 2003) and the northern Gulf of Mexico (black solid line, Milliken and Anderson, 2008). B. Sedimentary total nitrogen content (\%); boxplots illustrate total nitrogen in modern samples form the northern (up) and southern (down) sub-basins of the lagoon (whiskers show minimum and maximum scores). C. NMDS Axis 1 scores through time; boxplots illustrate scores of modern samples; scores of the modern environmental envelope represented by modern samples are highlighted in grey; scores of the interquartile range of samples from the well preserved southern sub-basin are in dark grey. D. Schematic development of La Mancha Lagoon, illustrated at 7,000, 6000, 4,500 cal BP, and Modern. 

Supplementary material for on-line publication only
Click here to download Supplementary material for o

Click here to download Supplementary material for on-line publication only: Cordero_etal_Supplementary material.docx

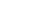

$x$

